\title{
Temperature-dependent dynamic moduli of Parylene-C columnar microfibrous thin films
}

\author{
Chandraprakash Chindam, ${ }^{a, *}$ Nicole R. Brown, ${ }^{b}$ Akhlesh Lakhtakia, ${ }^{a}$ \\ Osama O. Awadelkarim, ${ }^{a}$ and Wasim Orfali ${ }^{c}$ \\ ${ }^{a}$ Department of Engineering Science and Mechanics, Pennsylvania State University, University Park, PA \\ 16802, USA \\ ${ }^{b}$ Department of Agricultural and Biological Engineering, The Pennsylvania State University, University \\ Park, PA 16802, USA \\ ${ }^{c}$ Architectural Engineering Department, College of Engineering, Taibah University, P.O. Box 344, \\ Al-Madina Al Munawara, Kingdom of Saudi Arabia \\ ${ }^{*}$ Corresponding author. E-mail: cuc262@psu.edu
}

\begin{abstract}
Columnar microfibrous thin films ( $\mu$ FTFs) of the polymer Parylene $\mathrm{C}$ with different microfiber inclination angles were fabricated using a physicochemical vapor deposition process whereby a collimated flux of hot monomers is obliquely directed towards a planar substrate. Each $\mu \mathrm{FTF}$ was then subjected to cyclic elastic loading in one of two orthogonal directions lying wholly in the substrate plane: either (i) normal or (ii) parallel to the morphologically significant plane of the $\mu \mathrm{FTF}$. Dynamic storage and loss moduli were determined in the 1 to $80 \mathrm{~Hz}$ frequency range for temperatures between $-40{ }^{\circ} \mathrm{C}$ and $125{ }^{\circ} \mathrm{C}$. For all the columnar $\mu \mathrm{FTFs}$, the storage and loss moduli for normal loading did not exceed their counterparts for parallel loading. All the columnar $\mu$ FTFs were found to be softer than a bulk film of Parylene C. In both bulk and columnar forms, Parylene $\mathrm{C}$ was found to be rheologically not simple.

Keywords: Parylene C, dynamic mechanical analysis, storage modulus, loss modulus, microfibrous film
\end{abstract}

\section{Introduction}

Thin films have been researched as optical, electrical, magnetic, chemical, mechanical, and thermal coatings for over 150 years [1]. These films range in thickness from a few angstroms (even molecular monolayers) to hundreds of micrometers, depending 
on the specific application. They are made of a wide variety of raw materials including metals, glasses, and polymers [2].

Parylene $\mathrm{C}$ is a polymer with long-standing industrial use for electrically insulating coatings [3] and moisture barriers [4]. Bulk films of Parylene C are fabricated on substrates using a physicochemical vapor deposition process devised originally by Gorham

10 [5]. Free of pin holes, these films are used as interconnects [6, 7] and in microelectromechanical systems [8]. They are known to withstand temperatures as high as $220{ }^{\circ} \mathrm{C}$ and are resistant to most solvents [3,9]. Accordingly, they are used as biomedical substrates $[4,10,11,12,13]$.

Microfibrous thin films ( $\mu$ FTFs) of Parylene $\mathrm{C}$ can be fabricated on substrates by a modification of the now-standard Gorham process $[14,15]$. An $\mu \mathrm{FTF}$ is porous, as it is an assembly of parallel microfibers of diameter $\sim 5 \mu \mathrm{m}$. The shape of the microfibers can be upright circular-cylindrical, slanted circular-cylindrical, chevronic, helical, etc. The spacing between neighboring microfibers on a smooth substrate is $\sim 3 \mu \mathrm{m}$, but almost any larger spacing between the microfibers can be obtained by pre-patterning the substrate [15]. The potential of these $\mu \mathrm{FTF}$ s for tissue growth [16] as for protein assays [17] has been experimentally established, and theoretical analysis indicates their promise for ultrasonic filters as well [18].

A $\mu$ FTF comprising microfibers of circular-cylindrical shape, whether upright or slanted with respect to the substrate plane, is called a columnar $\mu \mathrm{FTF}$. All microfibers 25 are inclined at an angle $\chi \in\left(0^{\circ}, 90^{\circ}\right]$ with respect to the substrate plane. We recently characterized the molecular and microstructural differences between columnar $\mu \mathrm{FTFs}$ and bulk films of Parylene C [19]. Whereas bulks films are $83 \%$ crystalline and have only one crystal plane, the columnar $\mu \mathrm{FTFs}$ have $55-68 \%$ crystallinity and four crystal planes. However, the static contact angles of water droplets on columnar $\mu$ FTFs were similar to the static contact angles of water droplets on the bulk films [19].

Biological cells growing on a substrate subject the latter to contractile stress [20, 21]. Likewise, service as biomedical assays and ultrasonic filters will be stressful. Parylene-C $\mu$ FTFs also show promise as multifunctional materials [22, 23]. Therefore, although comprehensive knowledge of the mechanical properties of $\mu$ FTFs of Parylene $\mathrm{C}$ would be useful for these applications, only a preliminary report on just 


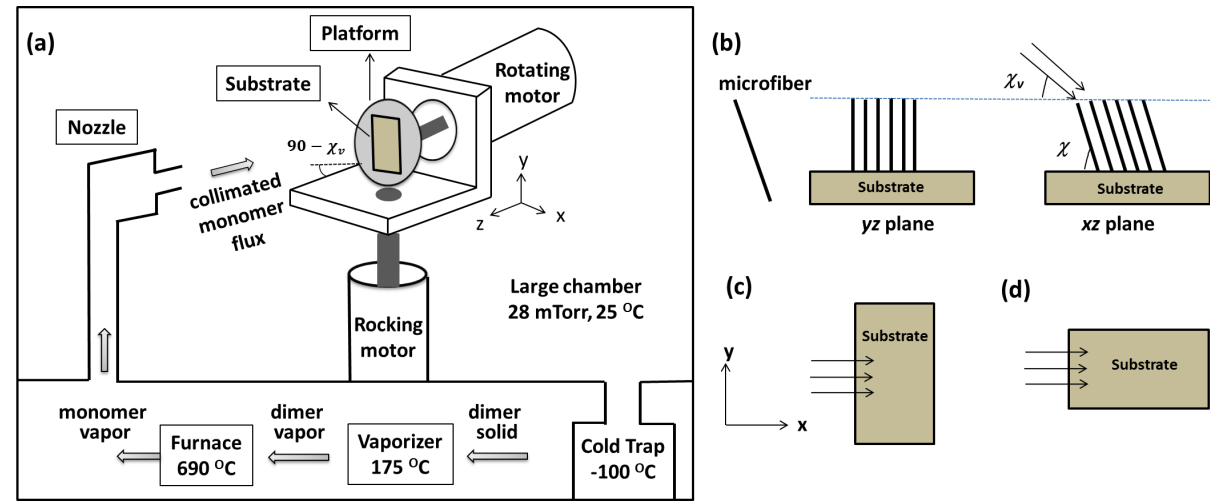

Figure 1: (a) Schematic of the process to deposit columnar $\mu$ FTFs of Parylene C. (b) Planar view of $\mu$ FTF on Si substrate in $x z$ and $y z$ planes. The angle $\chi_{v}$ of the collimated monomer flux with respect to the plane of the Si substrate and the microfiber inclination angle $\chi$ are marked. For each value of $\chi_{v}$ chosen, one substrate was aligned as shown in (c) and the other as shown in (d) during deposition.

one columnar $\mu \mathrm{FTF}$ has been published as yet [24]. Moreover, for day-to-day applications, these properties should be determined as functions of both temperature and frequency.

In this paper, we report our experimental investigation of the frequency- and temperature-dependent storage and loss moduli of columnar $\mu$ FTFs of Parylene $\mathrm{C}$ (grown on planar substrates) subjected to cyclic elastic loading in one of two orthogonal directions lying wholly in the substrate plane: either (i) normal or (ii) parallel to the morphologically significant plane (MSP) of the $\mu \mathrm{FTF}$. The storage and loss moduli for normal loading are denoted by $E_{\perp}^{\prime}$ and $E_{\perp}^{\prime \prime}$, while those for parallel loading are denoted by $E_{\|}^{\prime}$ and $E_{\|}^{\prime \prime}$. We determine the dependences of all the measured moduli on the microfiber inclination angle $\chi$.

The plan of this paper is as follows. In Sec. 2.1 we describe the procedure for fabricating the columnar $\mu$ FTFs of Parylene C. Next, in Sec. 2.3 we describe the mechanical experiments to determine $E_{\perp, \|}^{\prime}$ and $E_{\perp, \|}^{\prime \prime}$. The measured data are presented and discussed in Sec. 3. 
(a)

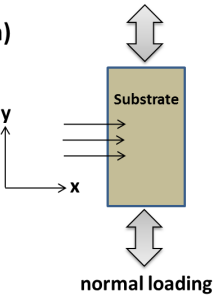

(b)

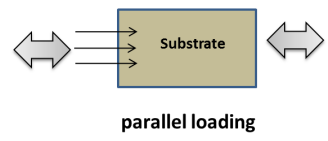

Figure 2: (a) Normal loading of a columnar $\mu \mathrm{FTF}$ and (b) parallel loading of a columnar $\mu \mathrm{FTF}$, both fabricated with the same value of $\chi_{v}$.

\section{Materials and Methods}

\subsection{Fabrication of columnar $\mu \mathrm{FTF} s$}

A $2.5 \times 1.3 \mathrm{~cm}^{2}$ substrate of silicon $(\mathrm{Si})$ was cleaned first for $10 \mathrm{~min}$ with acetone, then for 10 min with deionized (DI) water, then for $10 \mathrm{~min}$ isopropyl alcohol, and finally for 10 min with DI water. The substrate was then attached to a platform mounted on a motor assembly placed inside the large chamber of the PDS 2010 Labcoater (Specialty Coatings and Systems, Indianapolis, IN, USA), as shown schematically in Fig. 1(a). The shaft of the rocking motor in the assembly was oriented so that, during deposition, a collimated monomer flux of Parylene $\mathrm{C}$ would be obliquely incident on the substrate at an angle $\chi_{v} \in\left(0^{\circ}, 90^{\circ}\right]$ with respect to the substrate plane, as shown in Fig. 1(b). To fabricate the columnar $\mu \mathrm{FTF}, 4 \mathrm{~g}$ of solid Parylene-C dimer (Specialty Coatings and Systems, Indianapolis, IN, USA) contained in a semi-cylindrical aluminum boat was placed in the vaporizer of PDS 2010 Labcoater. The chamber was then pumped down to 28 mTorr. In an automated process, the solid dimer was sublimated to gaseous form in the vaporizer held at $175^{\circ} \mathrm{C}$. This vapor of dimers was passed into a furnace, held at $690{ }^{\circ} \mathrm{C}$, where it was dissociated into monomers [5]. This monomer flux was collimated by passage through a pipe and released through a nozzle towards the Si substrate. The monomers condensed on the substrate to form an assembly of slanted microfibers.

Let the MSP of a columnar $\mu \mathrm{FTF}$, which is the plane defined by the direction of the collimated monomer flux and the direction of inclination of the microfibers, be denoted 

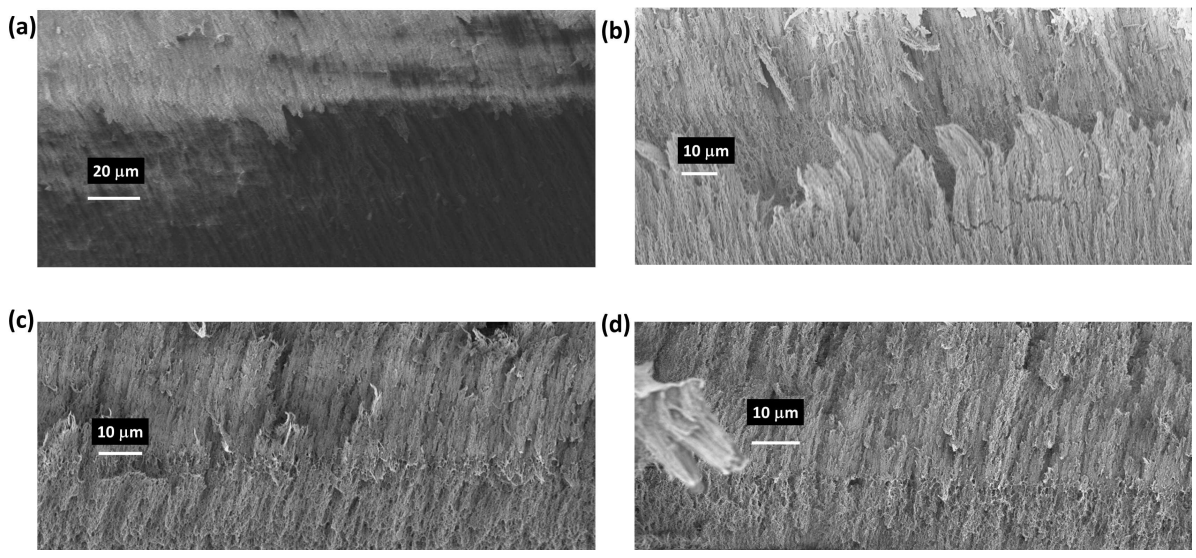

Figure 3: Cross-sectional SEM images of the MSPs of columnar $\mu$ FTFs fabricated with (a) $\chi_{v}=30^{\circ}$, (b) $\chi_{v}=52.5^{\circ}$, (c) $\chi_{v}=67.5^{\circ}$, and (d) $\chi_{v}=80^{\circ}$.

as the $x z$ plane, while the substrate plane be denoted as the $x y$ plane. In a predecessor study on columnar $\mu$ FTFs of Parylene $\mathrm{C}$ grown with different $\chi_{v}$, the dependence of $\chi$ on $\chi_{v}$ was classified into four regimes as follows: $\chi$ varies very weakly with

$75 \chi_{v} \in\left(30^{\circ}, 45^{\circ}\right)$, increases linearly with $\chi_{v} \in\left(45^{\circ}, 58^{\circ}\right)$, varies very weakly with $\chi_{v} \in\left(58^{\circ}, 75^{\circ}\right)$, and again increases linearly with $\chi_{v} \in\left(75^{\circ}, 90^{\circ}\right)[19$, Fig. $4 \mathrm{~b}]$. The $\mathrm{X}$-ray diffraction (XRD) spectrums of all columnar $\mu$ FTFs in each regime were found to be identical [19, Fig. 7]. Hence for this study, two columnar $\mu$ FTFs each were fabricated with $\chi_{v}=30^{\circ}, \chi_{v}=52.5^{\circ}, \chi_{v}=67.5^{\circ}$, and $\chi_{v}=80^{\circ}$, i.e., one in each of so the four regimes. For each chosen value of $\chi_{v}$, the substrate was aligned (i) as shown in Fig. 1(c) for one sample and (ii) as shown in Fig. 1(d) for one sample. In addition, one columnar $\mu \mathrm{FTF}$ was grown with $\chi_{v}=90^{\circ}$.

A bulk film was also deposited over a Si substrate but in the reduced capacity chamber of the PDS 2010 Labcoater, using $24 \mathrm{~g}$ of Parylene-C dimer. For this deposition, the motor assembly was not used and the nozzle was substituted by a baffle.

\subsection{Cross-sectional imaging}

Cross-sectional images of the MSPs of all columnar $\mu$ FTFs were taken using a scanning-electron microscope (SEM) [Model LEO 1530, Carl Zeiss, Darmstadt, Ger- 

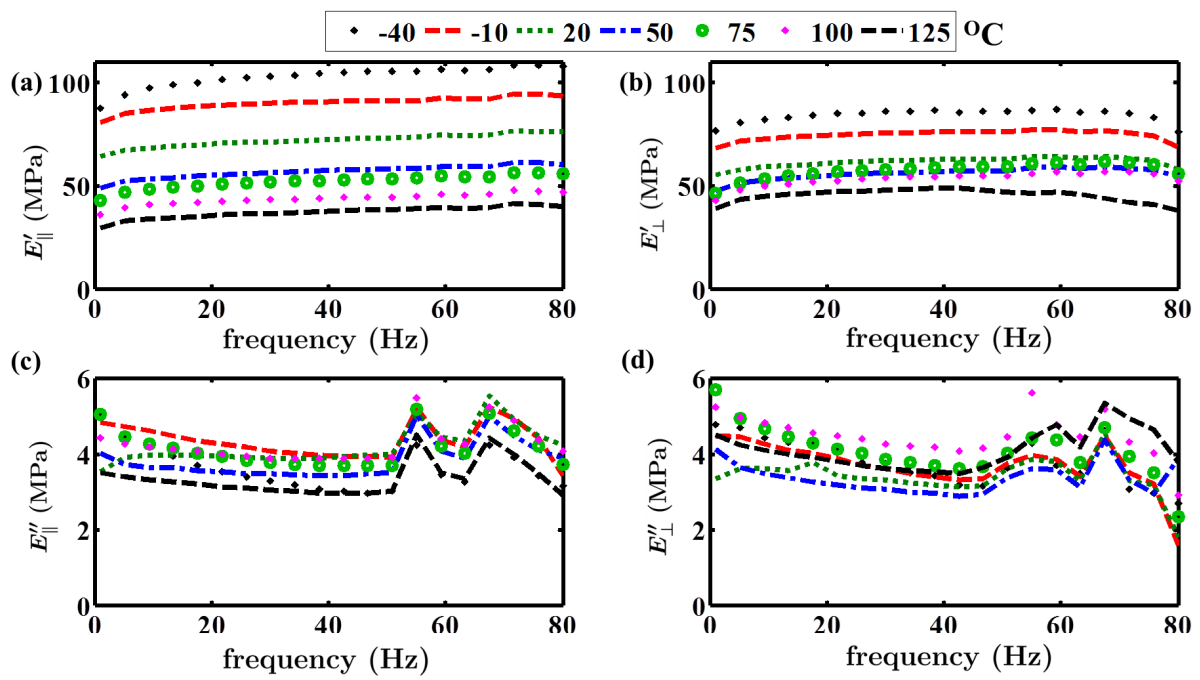

Figure 4: (a) $E_{\|}^{\prime}$, (b) $E_{\perp}^{\prime}$, (c) $E_{\|}^{\prime \prime}$, and (d) $E_{\perp}^{\prime \prime}$ at different temperatures for columnar $\mu \mathrm{FTF}$ of $\chi_{v}=30^{\circ}$. Numbers in the legend indicate temperatures.

many]. Each sample was first cleaved manually along the $x z$ plane and sputtered with

iridium in a sputter coater [Model K575X, Emitech, Fall River, MA,USA] on that plane for $28 \mathrm{~s}$ with $40 \mathrm{~mA}$ current. The SEM imaging software was used to measure $\chi$ with an accuracy of $\pm 0.1^{\circ}$.

\subsection{Mechanical testing}

The storage modulus is commonly determined by using profilometry data in the Stoney equation [25]. But this approach is limited to the measurement of the storage modulus of a homogeneous film in the thickness direction. Indentation methods using an atomic force microscope can only measure the local stiffness of the surface in the thickness direction [26]. Traditional optical methods using lasers [27], digital image correlation [28], and photoacoustic spectroscopy [29] are limited to room-temperature measurements, and the currently emerging moiré contouring technique's application for reliable measurements is time consuming [30]. Furthermore, those techniques which are capable of measurements at different temperatures require tedious instrumentation and fabrication procedures [31]. 

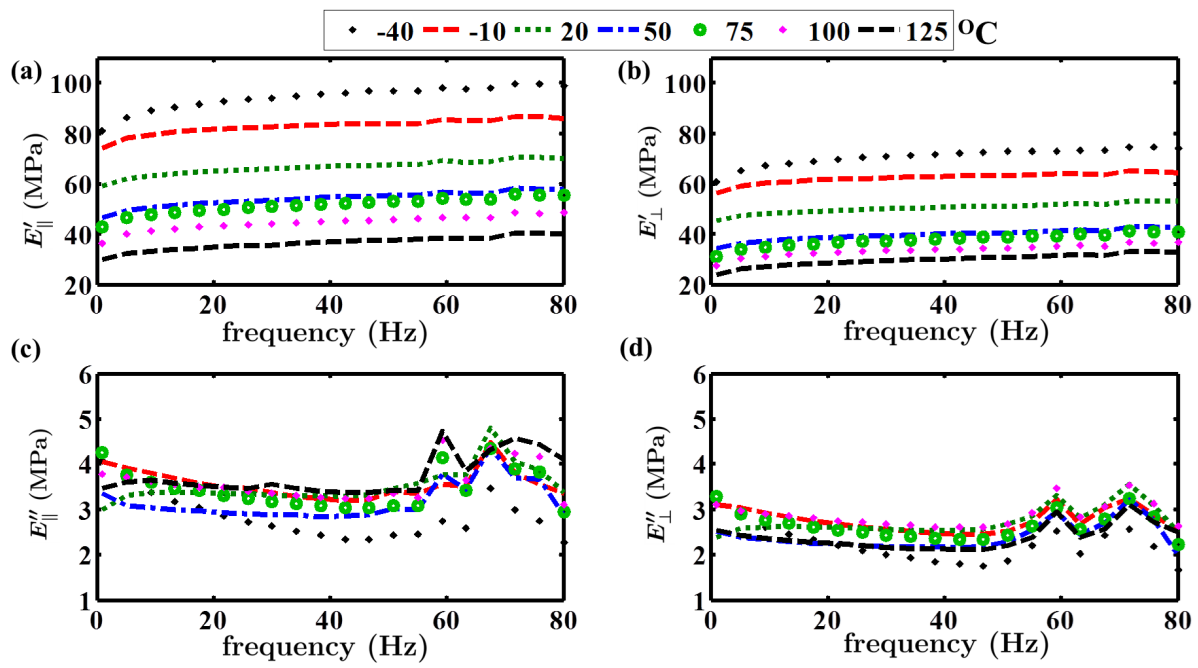

Figure 5: (a) $E_{\|}^{\prime}$, (b) $E_{\perp}^{\prime}$, (c) $E_{\|}^{\prime \prime}$, and (d) $E_{\perp}^{\prime \prime}$ at different temperatures for columnar $\mu \mathrm{FTF}$ of $\chi_{v}=52.5^{\circ}$. Numbers in the legend indicate temperatures.

We therefore decided to use a Dynamic Mechanical Analyzer (DMA) [Model Q800, TA Instruments, Newcastle, DE, USA] to measure $E_{\perp, \|}^{\prime}$ and $E_{\perp, \|}^{\prime \prime}$ over a range of frequencies and temperatures. In a preliminary study on a columnar $\mu \mathrm{FTF}$ grown with $\chi_{v}=45^{\circ}[24]$ we had measured $E_{\|}^{\prime}$ and $E_{\|}^{\prime \prime}$ using DMA, with the $\mu \mathrm{FTF}$ subjected to cyclic loads with a constant amplitude of deformation within the elastic regime at different frequencies $f$. For small deformations, i.e., in a linear material, the stress $\sigma=\sigma_{o} \sin (2 \pi f t)$ while the strain $\varepsilon=\varepsilon_{o} \sin (2 \pi f t+\delta)$ has a phase lag $\delta$; here, $\sigma_{o}$ and $\varepsilon_{o}$ are the respective amplitudes of stress and strain, and $t$ is time. Then, $E^{\prime}=\left(\sigma_{o} / \varepsilon_{o}\right) \cos \delta$ and $E^{\prime \prime}=\left(\sigma_{o} / \varepsilon_{o}\right) \sin \delta$ [32, Chap. 3]. The viability of using the DMA for columnar $\mu$ FTFs was established in the preliminary study [24], the measured value of the storage and loss moduli being different from their counterparts reported [9] for bulk films of Parylene C.

To determine $E_{\|}^{\prime \prime \prime}$ and $E_{\perp}^{\prime \prime \prime}$ of both columnar $\mu$ FTFs grown with the same value of $\chi_{v}$ per Figs. 1(c) and (d), the films were removed from the Si substrates with a razor moving along the $y$ and the $x$ directions, respectively. This was done to avoid curling of the columnar $\mu \mathrm{FTF}$ in the loading direction. After this, the columnar $\mu \mathrm{FTFs}$ 

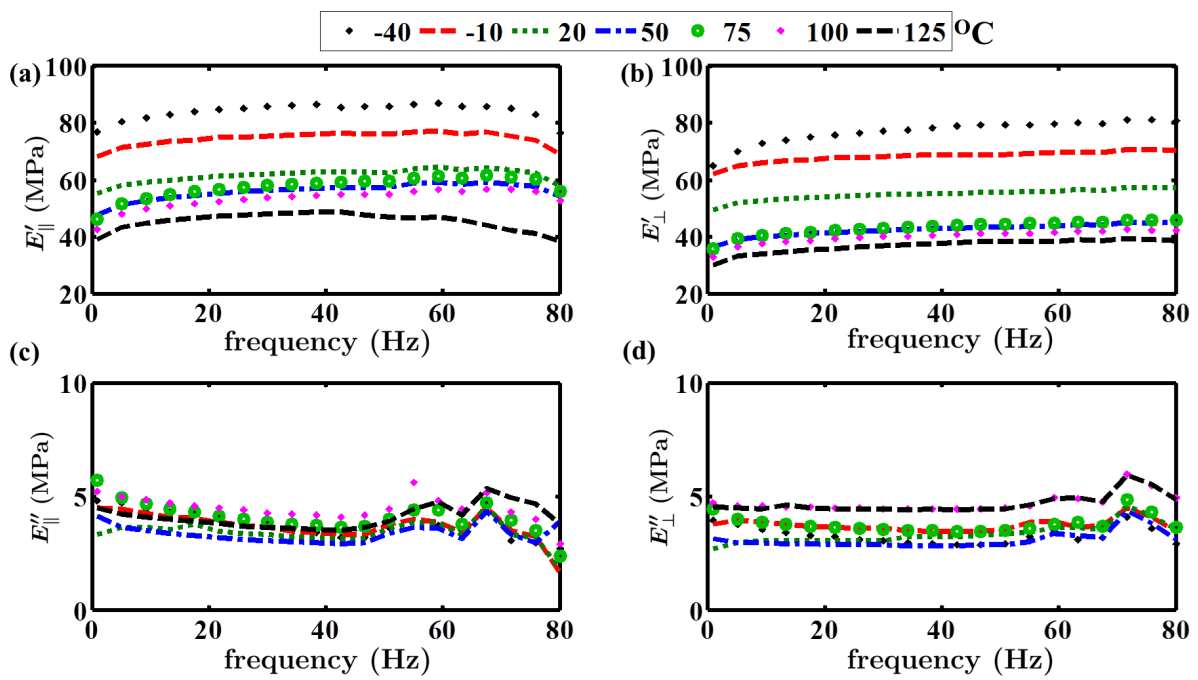

(d)

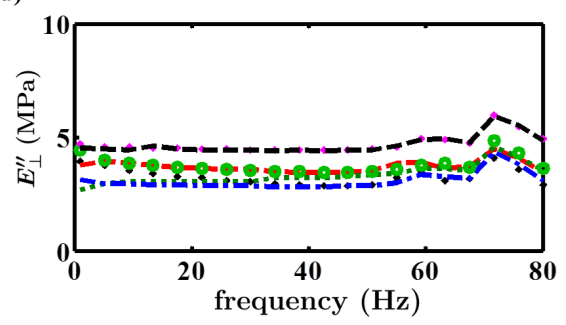

Figure 6: (a) $E_{\|}^{\prime}$, (b) $E_{\perp}^{\prime}$, (c) $E_{\|}^{\prime \prime}$, and (d) $E_{\perp}^{\prime \prime}$ at different temperatures for columnar $\mu \mathrm{FTF}$ of $\chi_{v}=67.5^{\circ}$. Numbers in the legend indicate temperatures.

were cut into rectangular shapes using glass slides and a razor, with the lengths of the samples lying between $5.84 \mathrm{~mm}$ and $7.37 \mathrm{~mm}$ and the widths between $4.33 \mathrm{~mm}$ and $6.38 \mathrm{~mm}$. The thickness and the width of each columnar $\mu \mathrm{FTF}$ were measured using digital vernier calipers. The lengths and the widths were chosen for each sample after initial experimentation with a room-temperature frequency sweep, in order to avoid the combined resonances of the sample and the DMA.

An initial strain-sweep test was performed at room temperature on all 10 samples to ensure that the amplitude of displacement $(10 \mu \mathrm{m})$ lay within the linear viscoelastic regime [32], i.e. $E_{\|, \perp}^{\prime \prime \prime}$ were independent of the applied strain. First, 'dynamic' and 'force' calibrations were performed on the DMA. Next, the tension-film clamp was calibrated for 'length' and 'stiffness', per protocol. The sample was loaded in the tension-film clamp and the length of the sample was read from the instrument screen. Values of the sample's width and thickness were fed to the 'Q800 DMA' software. The 'Temperature Step - Sweep Frequency' option in the 'Multi-frequency Strain' module was used. The temperature was set to vary from $-40{ }^{\circ} \mathrm{C}$ to $125^{\circ} \mathrm{C}$ in steps of $5{ }^{\circ} \mathrm{C}$. 

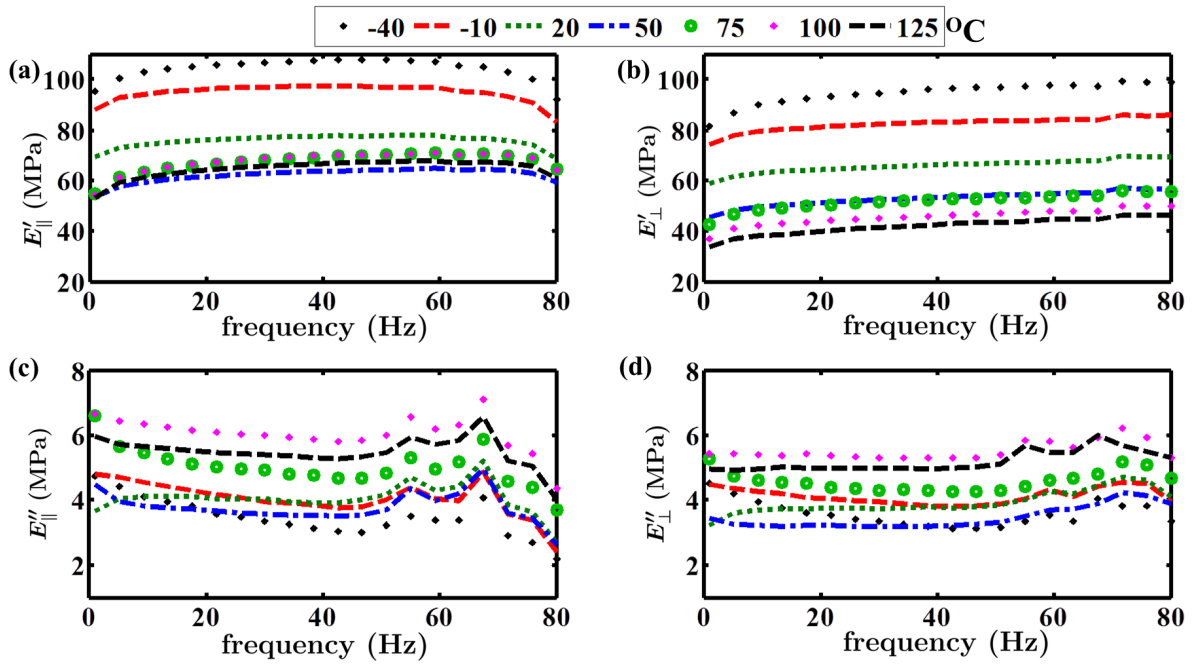

Figure 7: (a) $E_{\|}^{\prime}$, (b) $E_{\perp}^{\prime}$, (c) $E_{\|}^{\prime \prime}$, and (d) $E_{\perp}^{\prime \prime}$ at different temperatures for columnar $\mu \mathrm{FTF}$ of $\chi_{v}=80^{\circ}$. Numbers in the legend indicate the temperatures.

in order for thermal equilibrium to be attained. At each temperature, a displacement amplitude of $10 \mu \mathrm{m}$ was chosen for 20 linearly interpolated frequencies from $1 \mathrm{~Hz}$ to $80 \mathrm{~Hz}$. At each frequency, the amplitude was stabilized for 4 cycles, and then the force and displacement data for that frequency were collected over 3 cycles. Based on the force and displacement measured by the DMA and the dimensions of the sample, $E_{\|, \perp}^{\prime \prime \prime}$ were calculated by the 'Q800 DMA' software.

\section{Results and Discussion}

The cross-sectional SEM images of the MSPs of four columnar $\mu$ FTFs $\left(\chi_{v}<\right.$ $90^{\circ}$ ) are shown in Fig. 3. These images clearly show that each columnar $\mu \mathrm{FTF}$ is an assembly of parallel microfibers, as in previous papers [19, 24].

The measured values of $E_{\|, \perp}^{\prime \prime \prime}$ of the columnar $\mu$ FTFs with $\chi_{v} \in\left\{30^{\circ}, 52.5^{\circ}, 67.5^{\circ}\right.$, $\left.80^{\circ}\right\}$ at different temperatures are shown in Figs. 4-7. For the columnar $\mu$ FTF fabricated with $\chi_{v}=90^{\circ}$ and the bulk film, $E_{\|}^{\prime \prime \prime}=E_{\perp}^{\prime \prime \prime}=E^{\prime, \prime \prime}$ are similarly plotted in Fig. 8. 

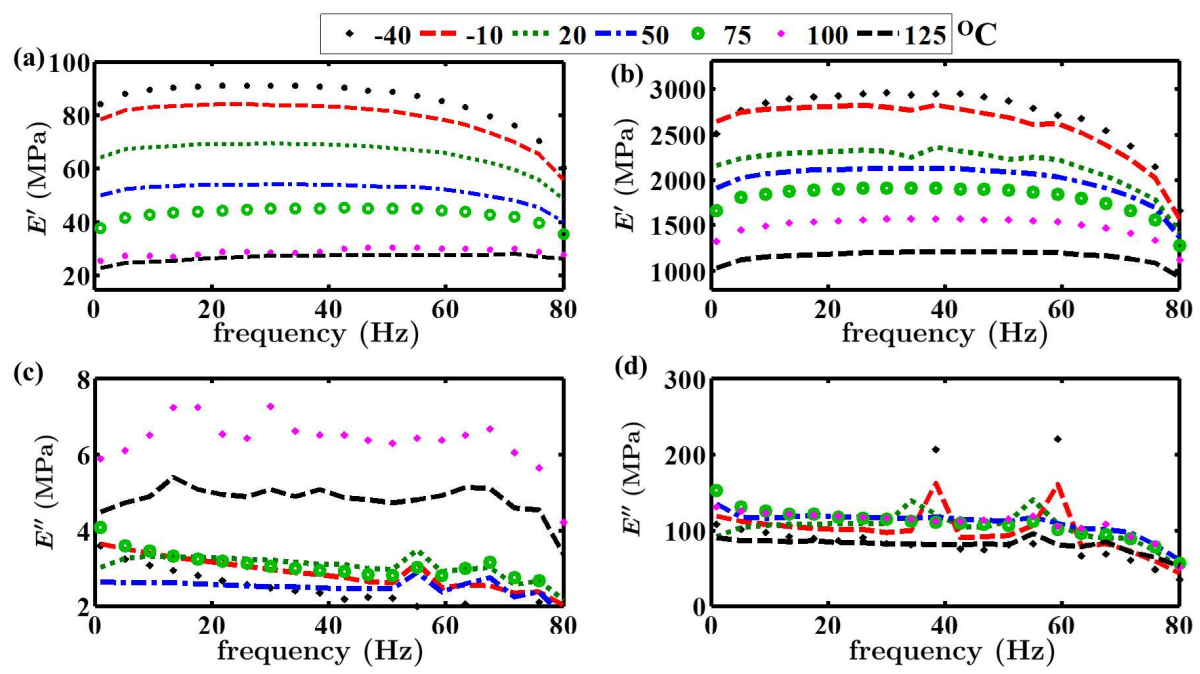

Figure 8: $E^{\prime}$ of (a) the columnar $\mu \mathrm{FTF}$ deposited with $\chi_{v}=90^{\circ}$ and (b) the bulk film. $E^{\prime \prime}$ of (c) the columnar $\mu \mathrm{FTF}$ deposited with $\chi_{v}=90^{\circ}$ and (d) the bulk film. Numbers in the legend indicate temperatures.
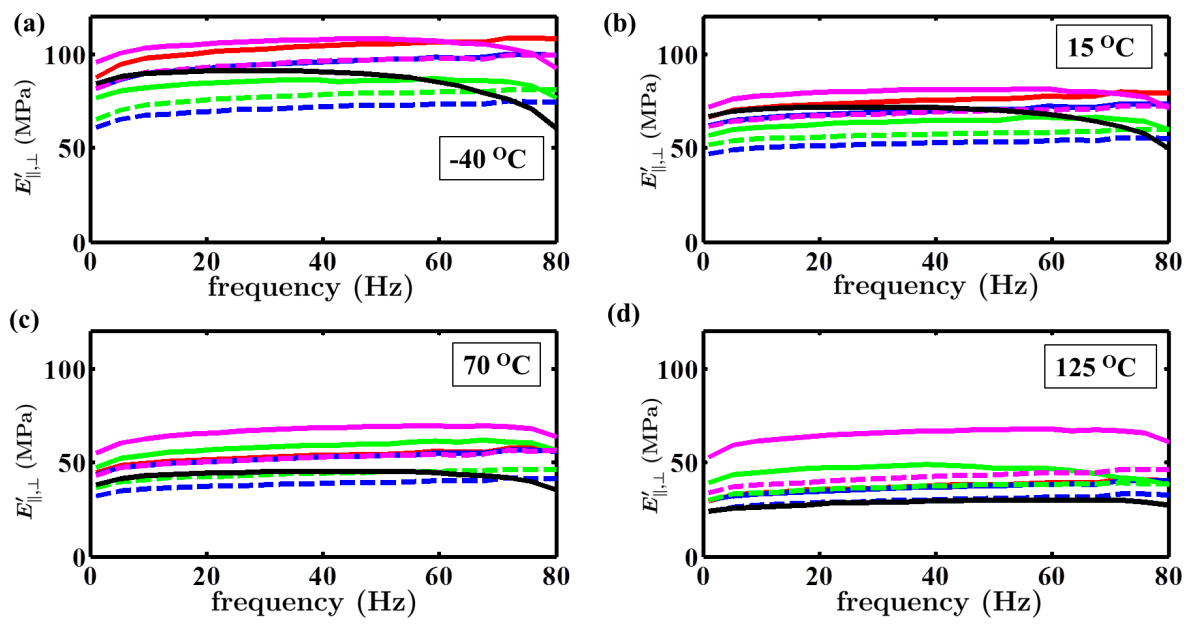

(d)

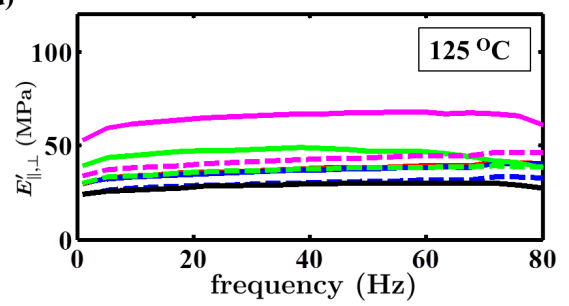

Figure 9: Comparison of $E_{\|}^{\prime}$ and $E_{\perp}^{\prime}$ of columnar $\mu$ FTFs at temperatures (a) $-40{ }^{\circ} \mathrm{C}$, (b) $15^{\circ} \mathrm{C}$, (c) $70{ }^{\circ} \mathrm{C}$, and (d) $125^{\circ} \mathrm{C}$. Solid lines represent $E_{\|}^{\prime}$, and dashed lines $E_{\perp}^{\prime}$. Red, blue, green, pink, and black curves represent columnar $\mu \mathrm{FTFs}$ fabricated with $\chi_{v}=30^{\circ}, 52.5^{\circ}, 67.5^{\circ}, 80^{\circ}$ and $90^{\circ}$, respectively. 

[9] and between $2.99 \mathrm{GPa}$ and $3.84 \mathrm{GPa}$ for bulk films grown in different vacuum conditions [33]. We found $E^{\prime}=2.15 \mathrm{GPa}$ for our bulk film at $1 \mathrm{~Hz}$ at room temperature, possibly due to different loading and deposition conditions.

For every columnar $\mu \mathrm{FTF}$ made by setting $\chi_{v}<90^{\circ}$, we found that $E_{\|}^{\prime}>E_{\perp}^{\prime}$, i.e., the columnar $\mu$ FTFs are stiffer in the $x z$ plane (MSP) than in the $y z$ plane (orthogonal to MSP). The excess of $E_{\|}^{\prime}$ over $E_{\perp}^{\prime}$ indicates that each microfiber tends to slide along its neighboring microfibers more during parallel loading than during normal loading, and that there is higher inter-microfiber friction in the MSP than in the $y z$ plane.

In the chosen frequency range, $E_{\|}^{\prime}$ increases weakly with frequency for all columnar $\mu \mathrm{FTFs}$ at all temperatures, unlike the bulk film whose $E^{\prime}$ slightly decreases with increase in frequency. More importantly, both $E_{\|, \perp}^{\prime}$ and $E_{\|, \perp}^{\prime \prime}$ for all columnar $\mu \mathrm{FTFs}$ $\left(\chi_{v} \in\left\{30^{\circ}, 52.5^{\circ}, 67.5^{\circ}, 80^{\circ}, 90^{\circ}\right\}\right)$ are at least 20 times lower than $E^{\prime}$ and $E^{\prime \prime}$, respectively, of the bulk film. Accordingly, the columnar $\mu$ FTFs are much softer than the bulk film. This observation can be explained in part by the fact that amorphous materials have a weak atomic bonding (and, hence, smaller storage moduli) compared to crystalline materials. The columnar $\mu$ FTFs were found to have lower crystallinity (from $55 \%$ to $68 \%$, depending on $\chi_{v}$ ) than the bulk film (83\%), as determined from XRD analysis [19]. Furthermore, the columnar $\mu$ FTFs have four crystal planes, whereas the bulk film has only one crystal plane [19]. More grain boundaries in a columnar $\mu \mathrm{FTF}$ should soften the material. Next, the cross-sectional diameter of a microfiber is $\sim 4.5 \mu \mathrm{m}$ and the center-to-center distance between neighboring microfibers is $\sim 7.5 \mu \mathrm{m}$. Hence, we estimate the porosity of a columnar $\mu \mathrm{FTF}$ to be $\sim 70 \%$. Moreover, the microfibers contain nanopores due to the physicochemical nature of the deposition process $[14,34]$. Thus, the porosities at the microscale and the nanoscale, the grain boundaries, and the amorphous nature of the columnar $\mu \mathrm{FTFs}$ account for their lower storage and loss moduli in comparison to those of the bulk film.

The low values of $E_{\|, \perp}^{\prime}$ of the columnar $\mu$ FTFs suggest their applicability for microfluidics [35]. Despite being softer than the bulk film of Parylene C, at room temperature the columnar $\mu$ FTFs are stiffer than bulk poly-dimethyl siloxane (PDMS), which has an (static) elastic modulus of $20 \mathrm{MPa}$ [36] and is commonly used in mi- 

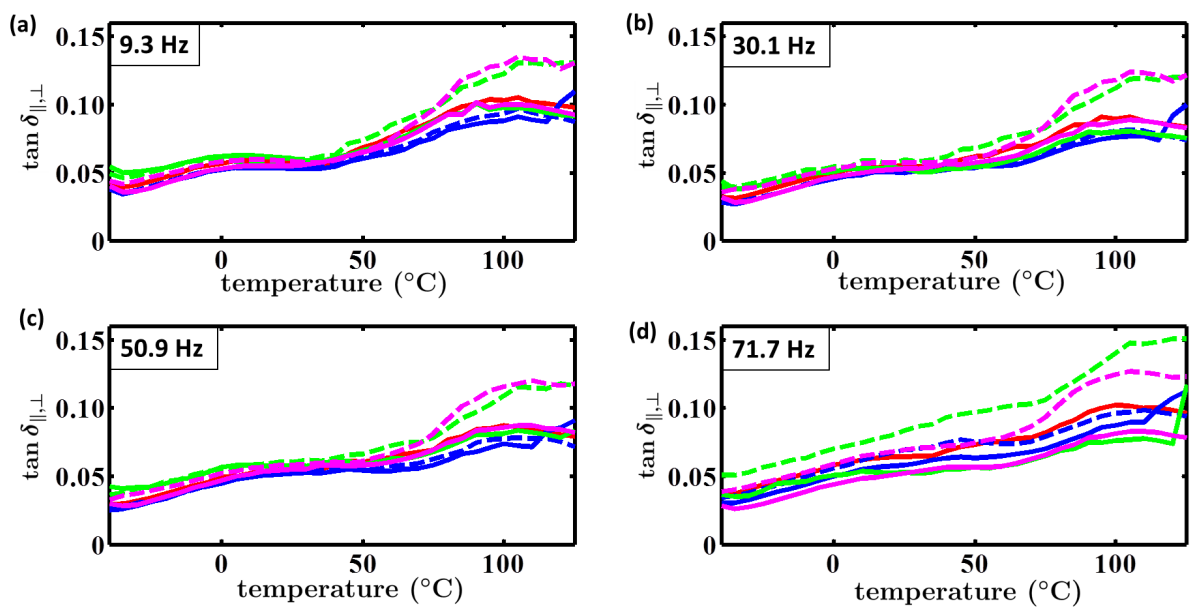

Figure 10: Comparison of $\tan \delta_{\|}$and $\tan \delta_{\perp}$ of columnar $\mu$ FTFs at (a) $9.3 \mathrm{~Hz}$, (b) $30.1 \mathrm{~Hz}$, (c) $50.9 \mathrm{~Hz}$, and (d) $71.7 \mathrm{~Hz}$. Solid lines represents $\tan \delta_{\|}$and dashed lines $\tan \delta_{\perp}$. Red, blue, green, and pink curves represent columnar $\mu \mathrm{FTFs}$ fabricated with $\chi_{v}=30^{\circ}, 52.5^{\circ}, 67.5^{\circ}$, and $80^{\circ}$, respectively.

crofluidics [37]. Since the $E_{\|, \perp}^{\prime}$ of the columnar $\mu$ FTFs of Parylene C lie in the MPa regime, they are also capable as synthetic scaffolds [16, 38].

An examination of the values of $E_{\|, \perp}^{\prime}$ of all columnar $\mu$ FTFs at four different temperatures $\left(-40{ }^{\circ} \mathrm{C}, 15{ }^{\circ} \mathrm{C}, 70{ }^{\circ} \mathrm{C}\right.$, and $\left.125{ }^{\circ} \mathrm{C}\right)$ in Fig. 9 suggests that $E_{\|, \perp}^{\prime}$ are nonlinearly dependent on $\chi_{v}$ and that the columnar $\mu \mathrm{FTF}$ fabricated with $\chi_{v}=90^{\circ}$ has the highest $E_{\|, \perp}^{\prime}$. Furthermore, we note that as $\chi_{v}$ increases, the difference $E_{\|}^{\prime}-E_{\perp}^{\prime}$ decreases at all temperatures.

For every columnar $\mu \mathrm{FTF}$ made by setting $\chi_{v}<90^{\circ}$, we found that $E_{\|}^{\prime \prime}>E_{\perp}^{\prime \prime}$. But their values are not very different in Figs. 4 to 8 , and are actually equal for $\chi_{v}=$ $90^{\circ}$. Furthermore, $E_{\|, \perp}^{\prime \prime}$ increase with $\chi_{v}$. As $\chi_{v}$ increases, the inter-microfiber spacing decreases and hence the contact friction between neighboring microfibers increases during loading, leading to higher $E_{\|, \perp}^{\prime \prime}$.

We observe two minor peaks in the curves of $E_{\|}^{\prime \prime}$ and $E_{\perp}^{\prime \prime}$ as functions of frequency. We call them minor peaks because the increments in $E_{\|}^{\prime \prime}$ and $E_{\perp}^{\prime \prime}$ are less than $2 \mathrm{MPa}$ and both $E_{\|}^{\prime}$ and $E_{\perp}^{\prime}$ have smooth variations. We suspect each of these peaks is due to a combined resonance of the sample and instrument. Although such peaks are known 
to occur at loading frequencies above $100 \mathrm{~Hz}$ for different materials, the low masses of our samples are causing the minor resonances to be observed below $100 \mathrm{~Hz}$.

Examining Fig. 10 for $\tan \delta_{\|}=E_{\|}^{\prime \prime} / E_{\|}^{\prime}$ and $\tan \delta_{\perp}=E_{\perp}^{\prime \prime} / E_{\perp}^{\prime}$ as functions of temperature, we note that all columnar $\mu \mathrm{FTF}$ have two peaks, similar to many bulk polymers [32, Sec. 7.3.1]. The lower-temperature-peak for four different frequencies of cyclic loading was found to lie either at $-5^{\circ} \mathrm{C}$ or $0^{\circ} \mathrm{C}$. The higher-temperature peak (averaged over the four frequencies of cyclic loading) was found to lie between $85{ }^{\circ} \mathrm{C}$ and $95{ }^{\circ} \mathrm{C}$ for parallel loading, and between $90{ }^{\circ} \mathrm{C}$ and $105^{\circ} \mathrm{C}$ for normal loading. Thus, there is a variation of $10{ }^{\circ} \mathrm{C}$ for the higher-temperature peak identified with the type of loading, frequency of loading, and also among the columnar $\mu$ FTFs grown with different values of $\chi_{v}$. Whether or not the higher-temperature peak can be designated as the glass transition temperature $T_{g}$ requires a shear test [39], but that turned out to be destructive. Further, we found the temperature peaks of bulk film to be the same as columnar $\mu$ FTFs based on similar plots as Fig. 10, but for bulk film. Published values of $T_{g}$ lie between $30^{\circ} \mathrm{C}$ and $60^{\circ} \mathrm{C}$ for $20 \mu \mathrm{m}$-thick bulk films [33], while one report has $T_{g}=92{ }^{\circ} \mathrm{C}$ for $5 \mu \mathrm{m}$-thick bulk films [40] and another report has $T_{g}=90{ }^{\circ} \mathrm{C}$ for $5.8 \mu \mathrm{m}$-thick bulk films [41] .

Time-Temperature Superposition (TTS) [42] was attempted over a narrow range of frequencies, $10 \mathrm{~Hz}$ to $50 \mathrm{~Hz}$, where $E_{\|, \perp}^{\prime}$ vary linearly with frequency for all the columnar $\mu$ FTFs and the bulk film. But smooth master curves for $E_{\|, \perp}^{\prime}$ with respect to frequency could not be constructed for any of the ten samples, which implies that neither the columnar $\mu$ FTFs nor the bulk film of Parylene $C$ are rheologically simple. This conclusion is in agreement with the literature that crystalline polymers are in general not rheologically simple [32, p. 251]. Both the bulk film and the columnar $\mu$ FTFs are crystalline, the former having a higher crystallinity than the columnar $\mu$ FTFs [19]. Indeed, the constructed TTS curve for any of the nine columnar $\mu \mathrm{FTFs}$ was found have less deviation from a theoretically smooth master curve than the constructed TTS curve for the bulk film. 


\section{Conclusion}

We note that for all the columnar microfibrous films, independent of the angle $\chi_{v}$ of the collimated monomer flux with respect to the substrate plane, the storage modulus in the morphologically significant plane is higher than in the vertical plane orthogonal to the MSP. All of the columnar $\mu$ FTFs have storage and loss moduli lower than those of the bulk film. The temperature peaks in the loss moduli of the columnar $\mu$ FTFs and bulk film were found to lie between $85^{\circ} \mathrm{C}$ and $105^{\circ} \mathrm{C}$. Parylene $\mathrm{C}$ in the bulk as well as the microfibrous forms was found to be rheologically not simple. A knowledge of these properties will help in desiging MEMS, towards the larger goal of developing microfibrous multifunctional metamaterials of Parylene C [23] and for biomedical applications in particular.

\section{Acknowledgements}

We acknowledge the use of facilities operated by the Pennsylvania State University Materials Research Institute, which is funded in part by the National Science Foundation Cooperative Agreement No. ECS-0335765. We thank the President and the Council of the Taibah University, Kingdom of Saudi Arabia for financial support.

\section{References}

[1] D.L. Smith. Thin-film Deposition: Principles and Practice. McGraw-Hill. 1995

[2] D. Laaber, H.-J. Bart. Chemical and pressure stress resistance of polymer films. Polym Test 2014;40(1):280. http://dx.doi.org/10.1016/j. polymertesting.2014.09.018

[3] J.J. Licari. Coating Materials for Electronic Applications: Polymers, Processes, Reliability, Testing. Noyes Publications. 2003. http://dx.doi.org/10. 1016/B978-081551492-3.50001-5

[4] D.C. Rodger, Y.-C. Tai. Microelectronic packaging for retinal prostheses. IEEE Eng Med Biol Mag 2005;24(5):52. http://dx.doi.org/10.1109/ MEMB.2005.1511500 
[5] W.F. Gorham. A new, general synthetic method for the preparation of linear polyp-xylylenes. J Polym Sci A Polym Chem 1966;4(12):3027. http: / / dx . doi . org/10.1002/pol.1966.150041209

[11] V.N. Vernekar, D.K. Cullen, N. Fogleman, Y. Choi, A.J. García, M.G. Allen, G.J. Brewer, M.C. LaPlaca. SU-8 2000 rendered cytocompatible for neuronal bioMEMS applications. J Biomed Mater Res Part A 2009;89A(1):138. http: //dx.doi.org/10.1002/jbm.a.31839

[12] J.P. Seymour, Y.M. Elkasabi, H.-Y. Chen, J. Lahann, D.R. Kipke. The insulation performance of reactive parylene films in implantable electronic de- 
vices. Biomaterials 2009;30(31):6158. http://dx. doi.org/10.1016/j . biomaterials.2009.07.061

[13] X. Xie, L. Rieth, L. Williams, S. Negi, R. Bhandari, R. Caldwell, R. Sharma, P. Tathireddy, F. Solzbacher. Long-term reliability of $\mathrm{Al}_{2} \mathrm{O}_{3}$ and Parylene C bilayer encapsulated Utah electrode array based neural interfaces for chronic implantation. J Neural Eng 2014;11(2):1. http://dx.doi.org/10.1088/ $1741-2560 / 11 / 2 / 026016$

[14] S. Pursel, M.W. Horn, M.C. Demirel, A. Lakhtakia. Growth of sculptured polymer submicronwire assemblies by vapor deposition. Polymer 2005;46(23):9544. http://dx.doi.org/10.1016/j.polymer.2005.07.092

[15] L. Wei, A. Lakhtakia. Fabrication of free standing, three-dimensional, fibrous, thin film substrates of parylene C. Mater Res Innov 2013;17(2):129. http: / / dx.doi.org/10.1179/1433075X12Y.0000000044

[16] L. Wei, A. Lakhtakia, A.P. Roopnariane, T.M. Ritty. Human fibroblast attachment on fibrous parylene-C thin-film substrates. Mater Sci Eng C 2010;30(8):1252. http://dx.doi.org/10.1016/j.msec.2010.07.003

[17] L. Wei, E.A. Vogler, T.M. Ritty, A. Lakhtakia. A 2D surface morphologycomposition gradient panel for protein-binding assays. Mater Sci Eng C 2011;31(8):1861. http://dx.doi.org/10.1016/j.msec.2011.09. 001

[18] C. Chindam, A. Lakhtakia, O.O. Awadelkarim, W. Orfali. Acoustic scattering from microfibers of Parylene C. J Appl Phys 2014;116(13):134905). http: / / dx.doi.org/10.1063/1.4896946

[19] C. Chindam, N.M. Wonderling, A. Lakhtakia, O.O. Awadelkarim, W. Orfali. Microfiber inclination, crystallinity, and water wettability of microfibrous thin-film substrates of Parylene $\mathrm{C}$ in relation to the direction of the monomer vapor during fabrication. Appl Surf Sci 2015;345(1):145. http://dx. doi .org/10 . $1016 / j$.apsusc.2015.03.165 
[20] J. Köser, S. Gaiser, B. Müller. Contractile cell forces exerted on rigid substrates. Eur Cell Mater 2009;21():479.

[21] C.-M. Lo, H.-B. Wang, M. Dembo, Y.-1. Wang. Cell movement is guided by the rigidity of the substrate. Biophys J 2000;79(1):144. http://dx.doi.org/ $10.1016 / \mathrm{S} 0006-3495(00) 76279-5$

[22] P. Matic. Overview of multifunctional materials. Proc. SPIE. 2003;5053(1)61. http://dx.doi.org/10.1117/12.498546

[23] A. Lakhtakia. From bioinspired multifunctionality to mimumes. Bioinsp Biomim Nanobiomater 2015;4(3):168. http://dx.doi.org/10.1680/bbn.14 . 00034

[24] C. Chindam, A. Lakhtakia, N.R. Brown, W. Orfali, O.O. Awadelkarim. Frequency- and temperature-dependent storage and loss moduli of microfibrous thin films of Parylene C. Mater Lett 2014;116(1):296. http: / / dx . doi . org/ $10.1016 / j . m a t l e t .2013 .11 .054$

[25] G.C.A.M. Janssen, M.M. Abdalla, F. van Keulen, B.R. Pujada, B. van Venrooy. Celebrating the 100th anniversary of the Stoney equation for film stress: Developments from polycrystalline steel strips to single crystal silicon substrates. Thin Solid Films 2009;517(6):1858. http://dx.doi.org/10.1016/j.tsf. 2008.07 .014

[26] L.-Y. Lin, D.-E. Kim. Measurement of the elastic modulus of polymeric films using an AFM with a steel micro-spherical probe tip. Polym Test 2012;31(7):926. http://dx.doi.org/10.1016/j.polymertesting.2012.06. 012

[27] T.W. Murray, S. Krishnaswamy, J.D. Achenbach. Laser generation of ultrasound in films and coatings. Appl Phys Lett 1999;74(23):3561. http://dx.doi. org/10.1063/1.124161

[28] F. Grytten, H. Daiyan, M. Polanco-Loria, S. Dumoulin. Use of digital image correlation to measure large-strain tensile properties of ductile thermo- 
plastics. Polym Test 2009;28(6):653. http://dx.doi.org/10.1016/j . polymertesting.2009.05.009

[29] C.M. Hernandez, T.W. Murray, S. Krishnaswamy. Photoacoustic characterization of the mechanical properties of thin films. Appl Phys Lett 2002;80(4):691. http://dx.doi.org/10.1063/1.1434303

[30] F.M. Sciammarella, C.A. Sciammarella, L. Lamberti, M. Styrcula, L. Wei, A. Lakhtakia, Robust mechanical property measurements of fibrous parylene-C thinfilm substrate via moiré contouring technology. J Mech Behav Biomed Mater 2013;20(1):237. http://dx.doi.org/10.1016/j.jmbbm.2012.11. 017

[31] M.A. Haque, M.T.A. Saif. In situ tensile testing of nanoscale freestanding thin films inside a transmission electron microscope. J Mater Res 2005;20(7):1769. http://dx.doi.org/10.1557/JMR.2005.0220

[32] R.S Lakes. Viscoelastic Solids. CRC Press. 1999

[33] J.C.-H. Lin. MEMS for glaucoma. PhD Thesis. California Institute of Technology, Pasadena, CA (2012).

[34] A. Lakhtakia, R. Messier. Sculptured Thin Films: Nanoengineered Morphology and Optics. SPIE Press. 2005

[35] B.T. Good, S. Reddy, R.H. Davis, C.N. Bowman. Tailorable low modulus, reversibly deformable elastomeric thiol-ene materials for microfluidic applications, Sens Actuat B Chem 2007;120(2):473. http: / dx . doi.org/10.1016/j . snb.2006.02.040

[36] Z. Wang, A.A. Volinsky, N.D. Gallant. Crosslinking effect on polydimethylsiloxane elastic modulus measured by custom-built compression instrument. J Appl Polym Sci 2014;131(22):41050. http://dx.doi.org/10.1002/ APP. 41050 
[37] J.C. McDonald, G.M. Whitesides. Poly(dimethylsiloxane) as a material for fabricating microfluidic devices. Acc Chem Res 2002;35(7):491. http : / / dx . doi . org/10.1021/ar010110q

[38] B.L. Banik, G.S. Lewis, J.L. Brown. Multiscale Poly-( $\in$-caprolactone $)$ scaffold mimicking non-linearity in tendon tissue mechanics. Regen Eng Transl Med 2016.http://dx.doi.org/10.1007/s40883-016-0008-5

[39] A.J. Kovacs, R.A. Stratton, J.D. Ferry. Dynamical mechanical properties of polyvinyl acetate in shear in the glass transition temperature range. J Phys Chem 1963;67(1):152. http://dx.doi.org/10.1021/j100795a037

[40] T. Goda, T. Konno, M. Takai, K. Ishihara. Photoinduced phospholipid polymer grafting on Parylene film: Advanced lubrication and antibiofouling properties. Colloid Surf B: Biointerf 2007;54(1):67. http: / / dx . doi . org/10.1016/ j.colsurfb.2006.09.006

[41] A. Kahouli, A. Sylvestre, F. Jomni, B. Yangui, J. Legrand. Ac-conductivity and dielectric relaxations above glass transition temperature for parylene-C thin films. Appl Phys A 2012;106(4):909. http: / / dx . doi .org/10.1007/ s00339-011-6706-4

[42] M. van Gurp, J. Palmen. Time-temperature superposition for polymeric blends. Rheol Bull 1998;67(1):5. 


\section{Figure Captions}

Fig. 1: (a) Schematic of the process to deposit columnar $\mu$ FTFs of Parylene C. (b) Planar view of $\mu \mathrm{FTF}$ on Si substrate in $x z$ and $y z$ planes. The angle $\chi_{v}$ of the collimated monomer flux with respect to the plane of the Si substrate and the microfiber inclination angle $\chi$ are marked. For each value of $\chi_{v}$ chosen, one substrate was aligned as shown in (c) and the other as shown in (d) during deposition.

Fig. 2: (a) Normal loading of a columnar $\mu \mathrm{FTF}$ and (b) parallel loading of a columnar $\mu \mathrm{FTF}$, both fabricated with the same value of $\chi_{v}$.

Fig. 3: Cross-sectional SEM images of the MSPs of columnar $\mu$ FTFs fabricated with (a) $\chi_{v}=30^{\circ}$, (b) $\chi_{v}=52.5^{\circ}$, (c) $\chi_{v}=67.5^{\circ}$, and (d) $\chi_{v}=80^{\circ}$.

Fig. 4: (a) $E_{\|}^{\prime}$, (b) $E_{\perp}^{\prime}$, (c) $E_{\|}^{\prime \prime}$, and (d) $E_{\perp}^{\prime \prime}$ at different temperatures for columnar $\mu \mathrm{FTF}$ of $\chi_{v}=30^{\circ}$. Numbers in the legend indicate temperatures.

Fig. 5: (a) $E_{\|}^{\prime}$, (b) $E_{\perp}^{\prime}$, (c) $E_{\|}^{\prime \prime}$, and (d) $E_{\perp}^{\prime \prime}$ at different temperatures for columnar $\mu \mathrm{FTF}$ of $\chi_{v}=52.5^{\circ}$. Numbers in the legend indicate temperatures.

Fig. 6: (a) $E_{\|}^{\prime}$, (b) $E_{\perp}^{\prime}$, (c) $E_{\|}^{\prime \prime}$, and (d) $E_{\perp}^{\prime \prime}$ at different temperatures for columnar $\mu \mathrm{FTF}$ of $\chi_{v}=67.5^{\circ}$. Numbers in the legend indicate temperatures.

Fig. 7: (a) $E_{\|}^{\prime}$, (b) $E_{\perp}^{\prime}$, (c) $E_{\|}^{\prime \prime}$, and (d) $E_{\perp}^{\prime \prime}$ at different temperatures for columnar $\mu \mathrm{FTF}$ of $\chi_{v}=80^{\circ}$. Numbers in the legend indicate temperatures.

Fig. 8: $E^{\prime}$ of (a) the columnar $\mu \mathrm{FTF}$ deposited with $\chi_{v}=90^{\circ}$ and (b) the bulk film. $E^{\prime \prime}$ of (c) the columnar $\mu \mathrm{FTF}$ deposited with $\chi_{v}=90^{\circ}$ and (d) the bulk film. Numbers in the legend indicate temperatures.

Fig. 9: Comparison of $E_{\|}^{\prime}$ and $E_{\perp}^{\prime}$ of columnar $\mu$ FTFs at temperatures (a) $-40{ }^{\circ} \mathrm{C}$, (b) $15^{\circ} \mathrm{C}$, (c) $70^{\circ} \mathrm{C}$, and (d) $125^{\circ} \mathrm{C}$. Solid lines represent $E_{\|}^{\prime}$, and dashed lines $E_{\perp}^{\prime}$. 
Red, blue, green, pink, and black curves represent columnar $\mu$ FTFs fabricated with $\chi_{v}=30^{\circ}, 52.5^{\circ}, 67.5^{\circ}, 80^{\circ}$ and $90^{\circ}$, respectively.

Fig. 10: Comparison of $\tan \delta_{\|}$and $\tan \delta_{\perp}$ of columnar $\mu$ FTFs at (a) $9.3 \mathrm{~Hz}$, (b) $30.1 \mathrm{~Hz}$, (c) $50.9 \mathrm{~Hz}$, and (d) $71.7 \mathrm{~Hz}$. Solid lines represents $\tan \delta_{\|}$and dashed lines $\tan \delta_{\perp}$. Red, blue, green, and pink curves represent columnar $\mu$ FTFs fabricated with $\chi_{v}=30^{\circ}, 52.5^{\circ}, 67.5^{\circ}$, and $80^{\circ}$, respectively. 


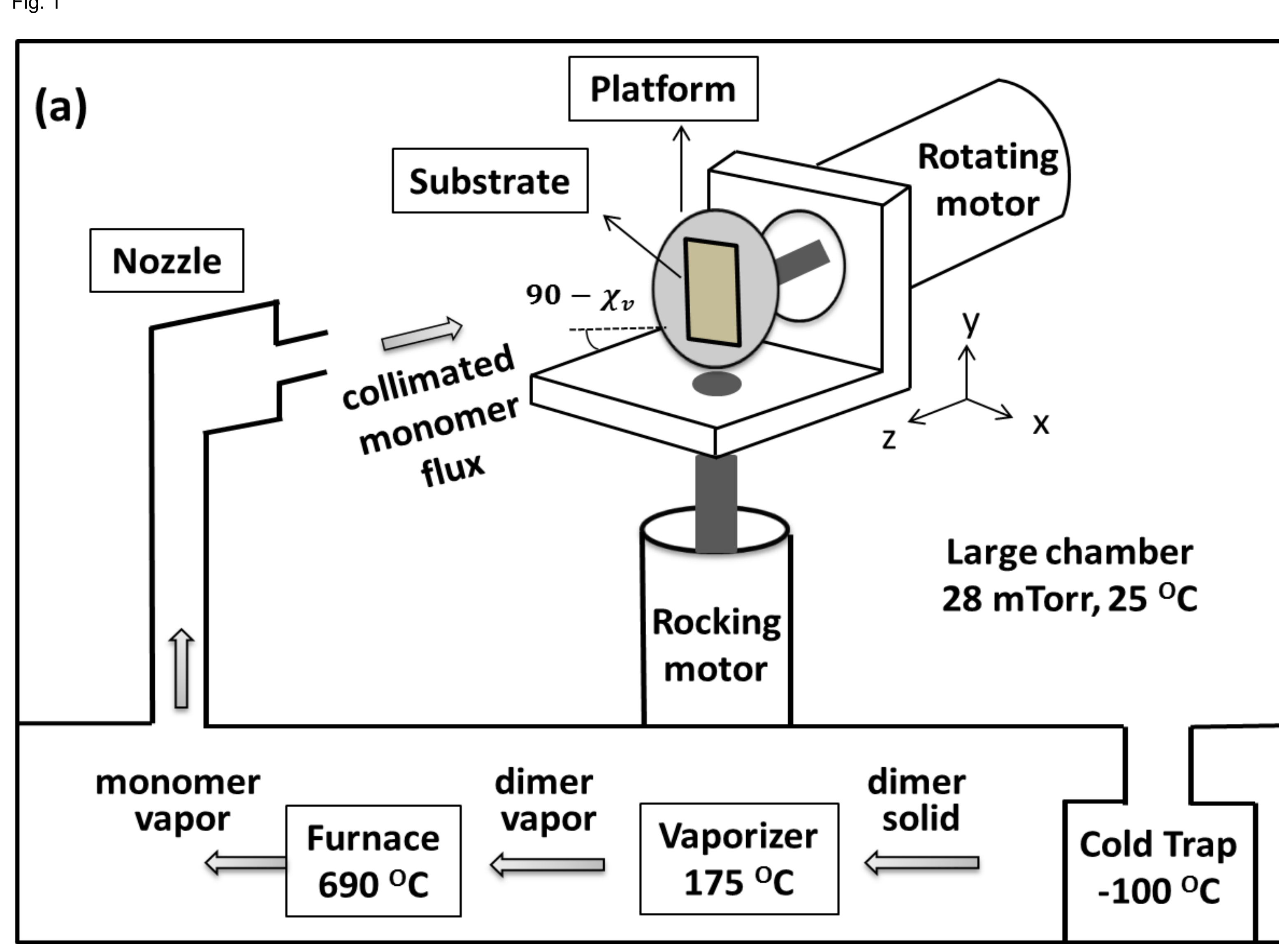

(b)

microfiber
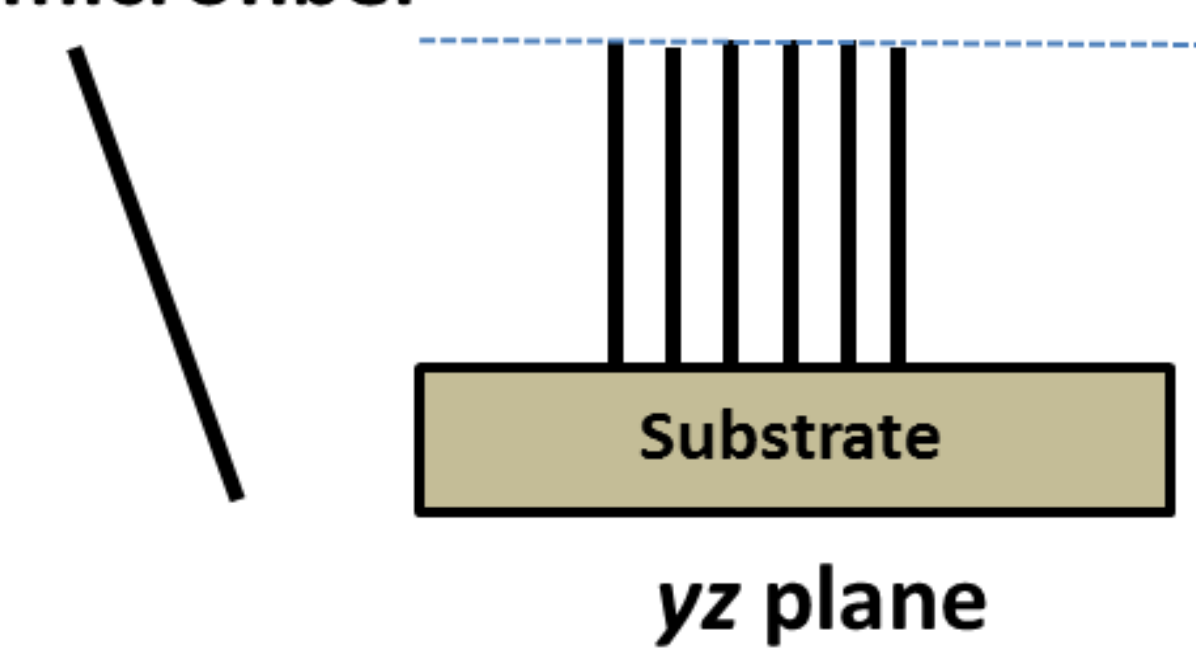

(c)

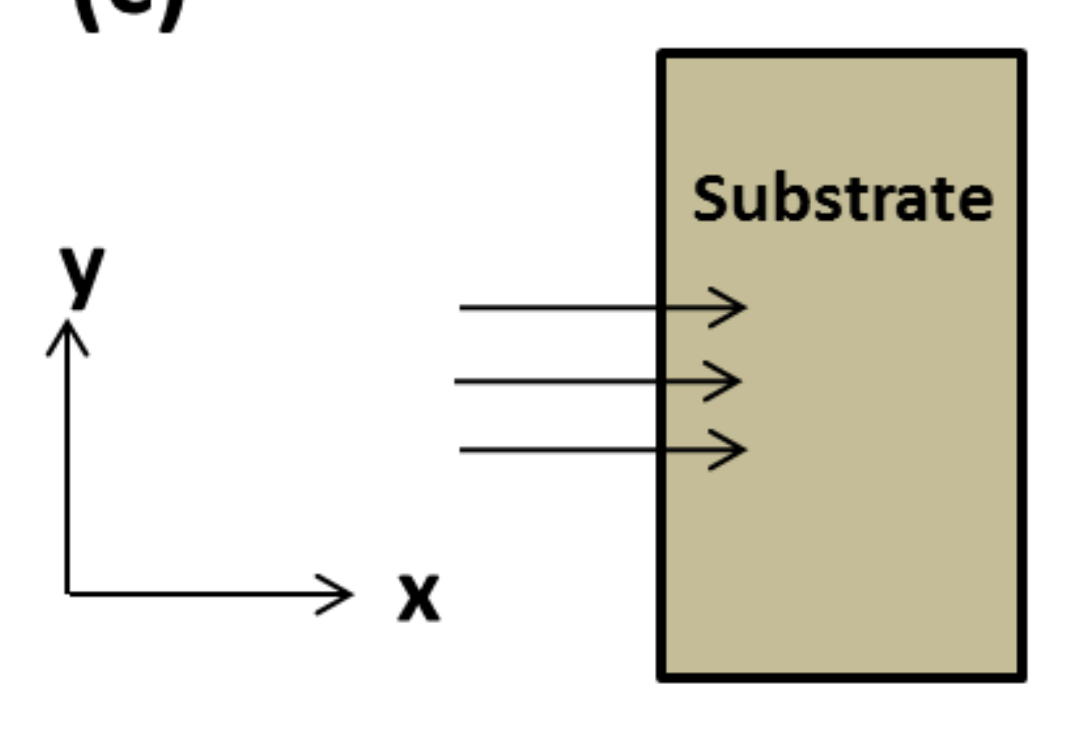

$\chi_{v}$

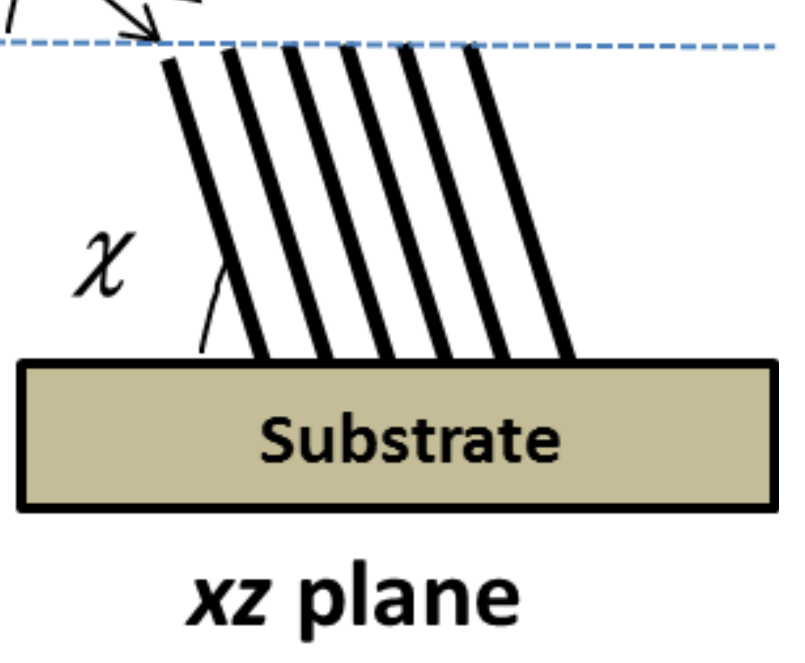

(d)

Substrate 
Fig. 2

(a)

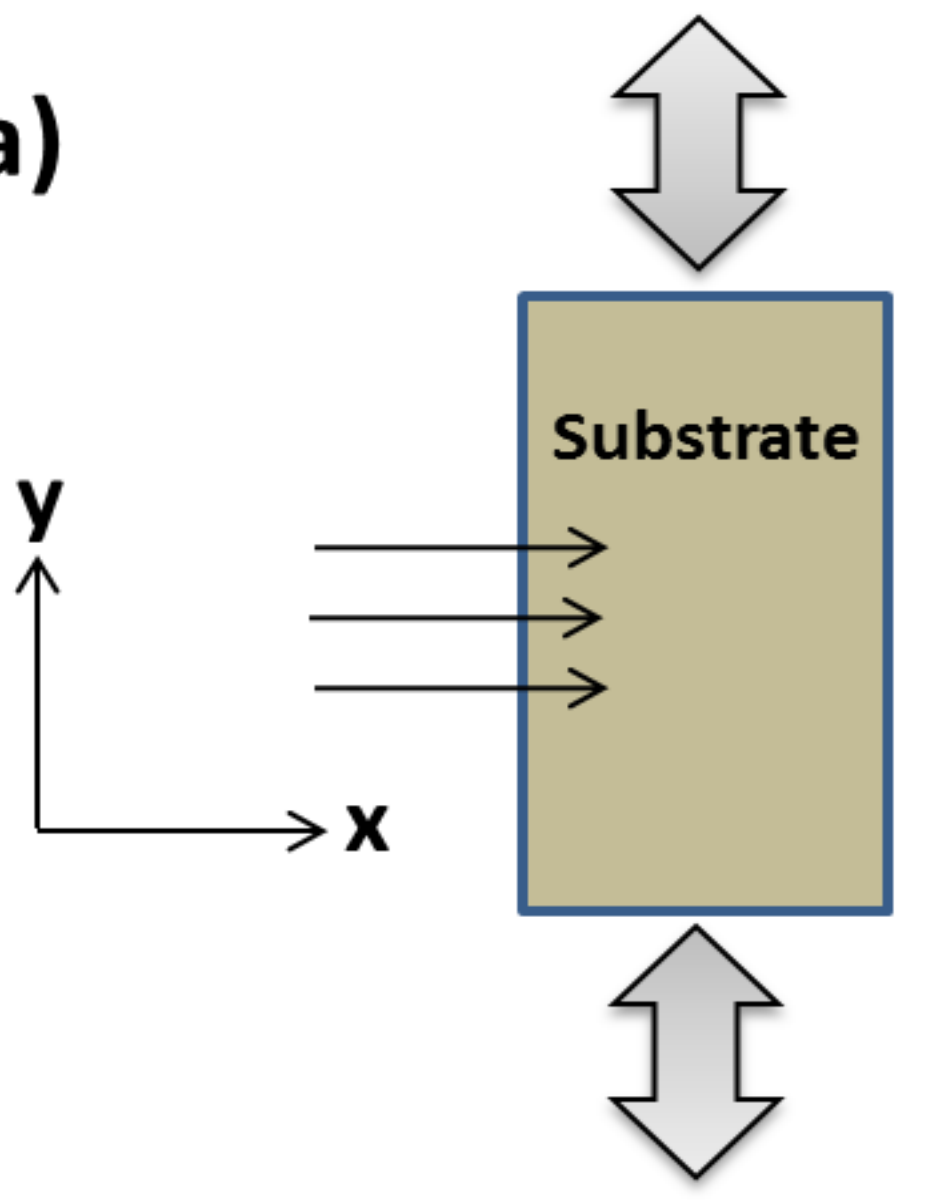

(b)
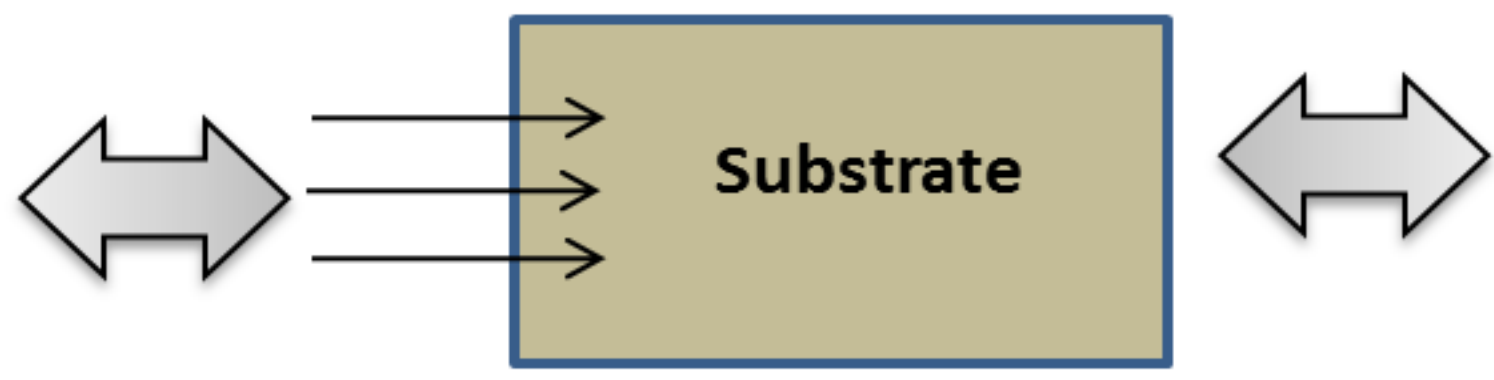
parallel loading

normal loading 
(a)

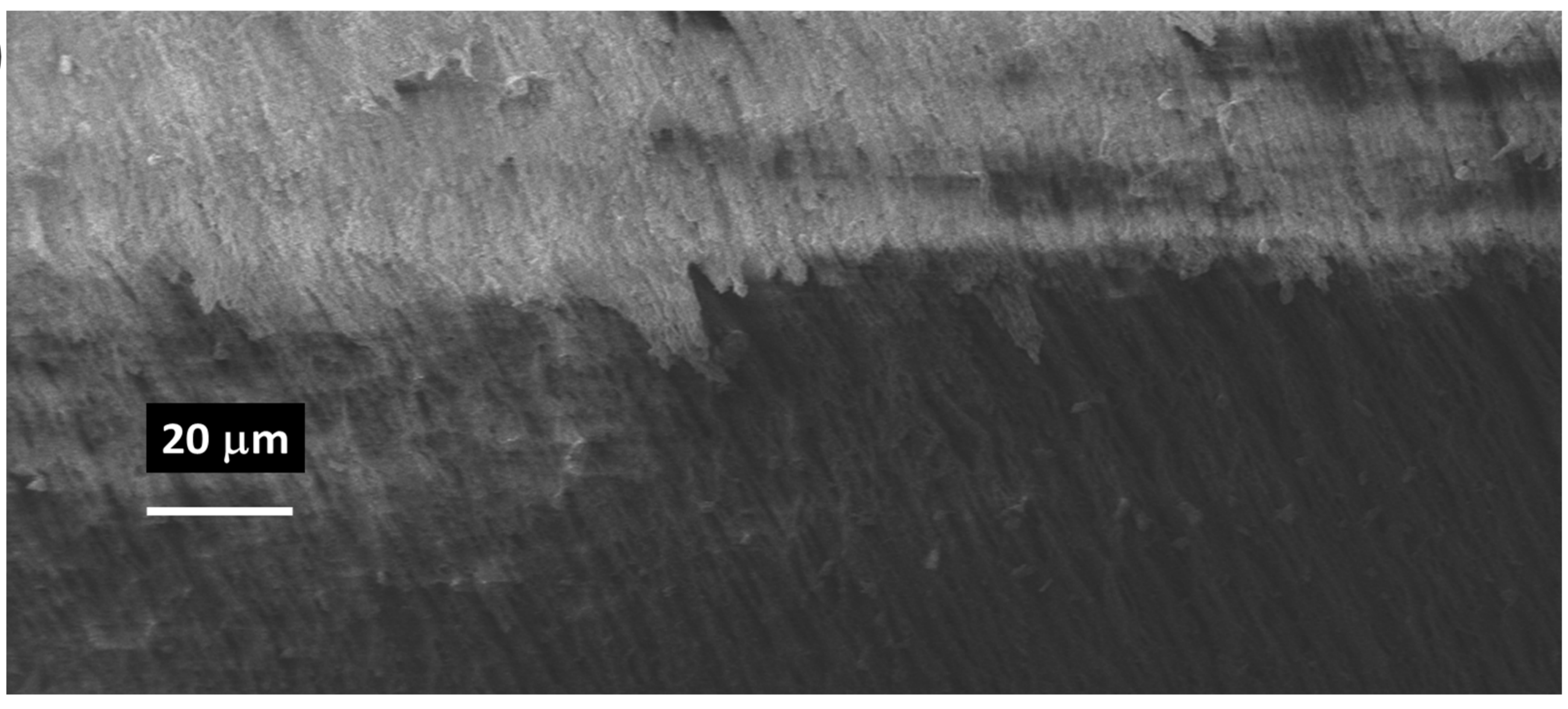

(b)

(c)

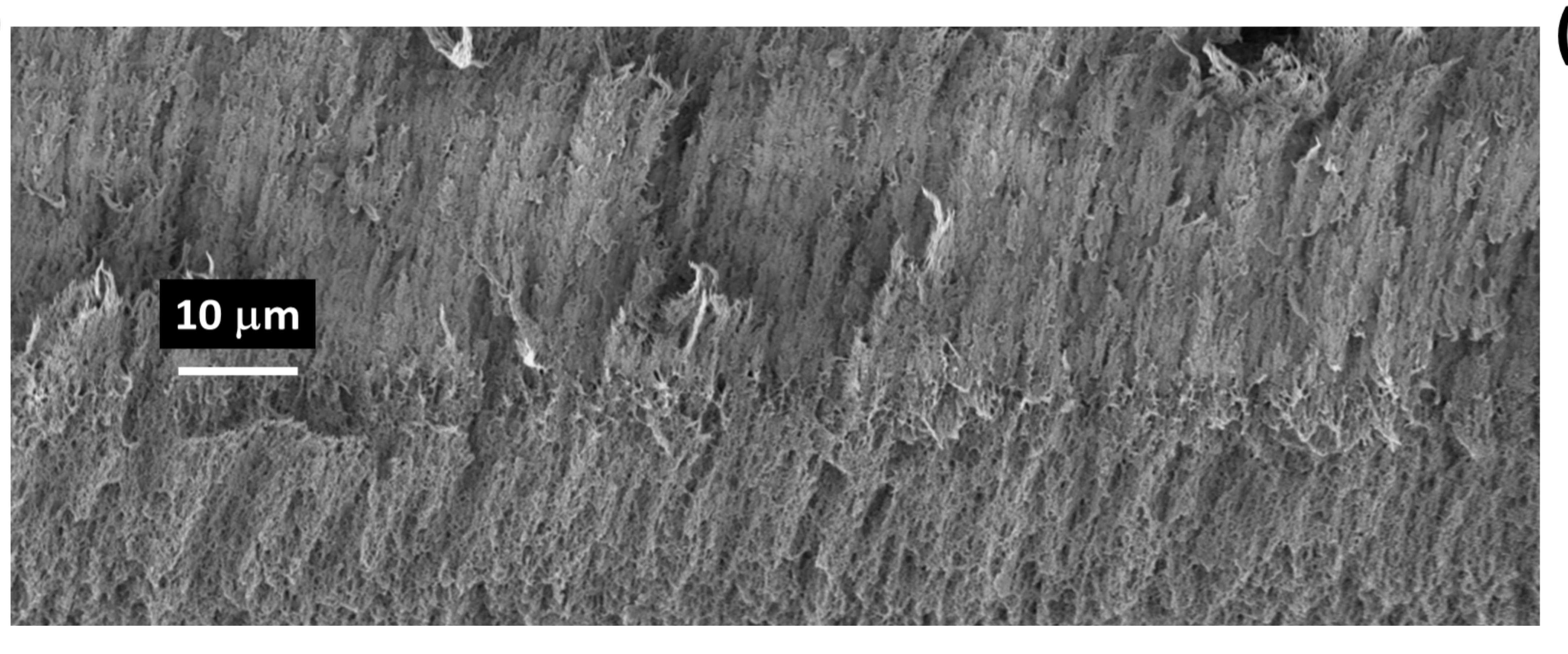

(d)

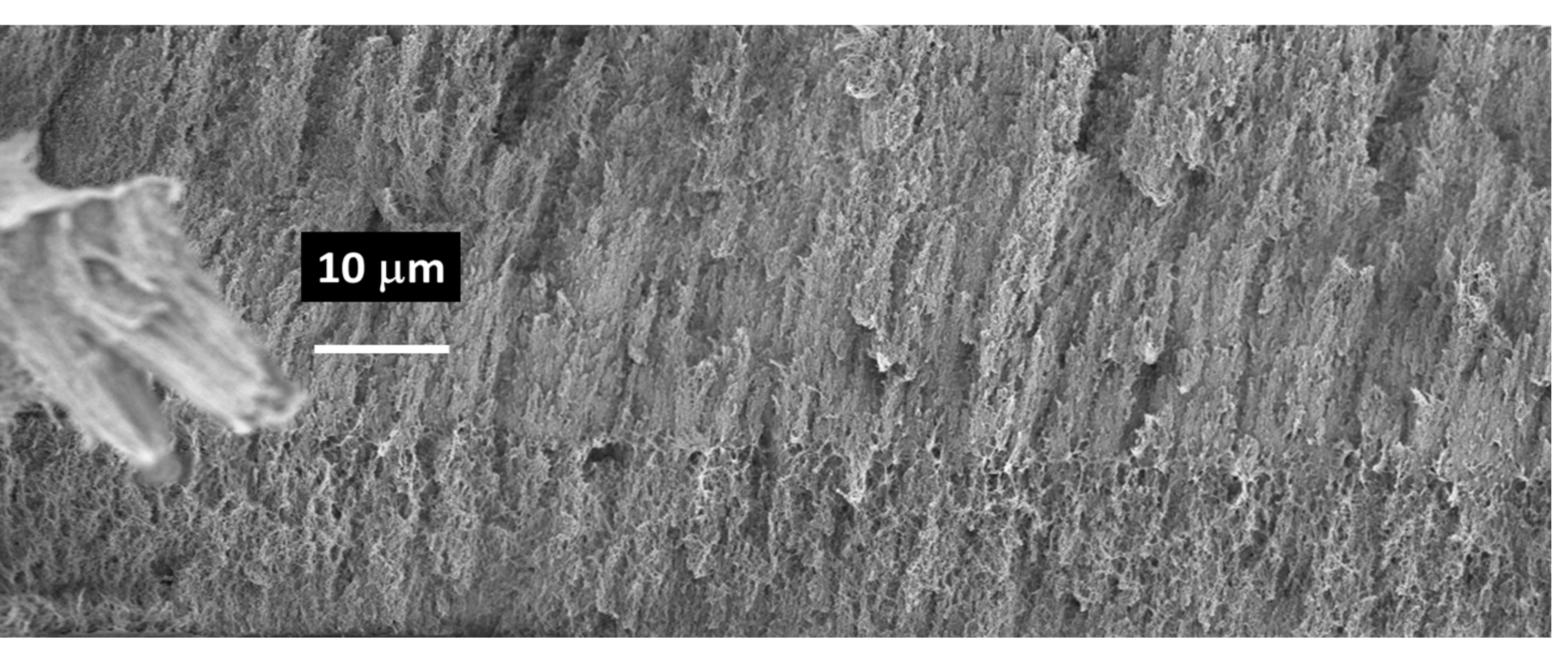




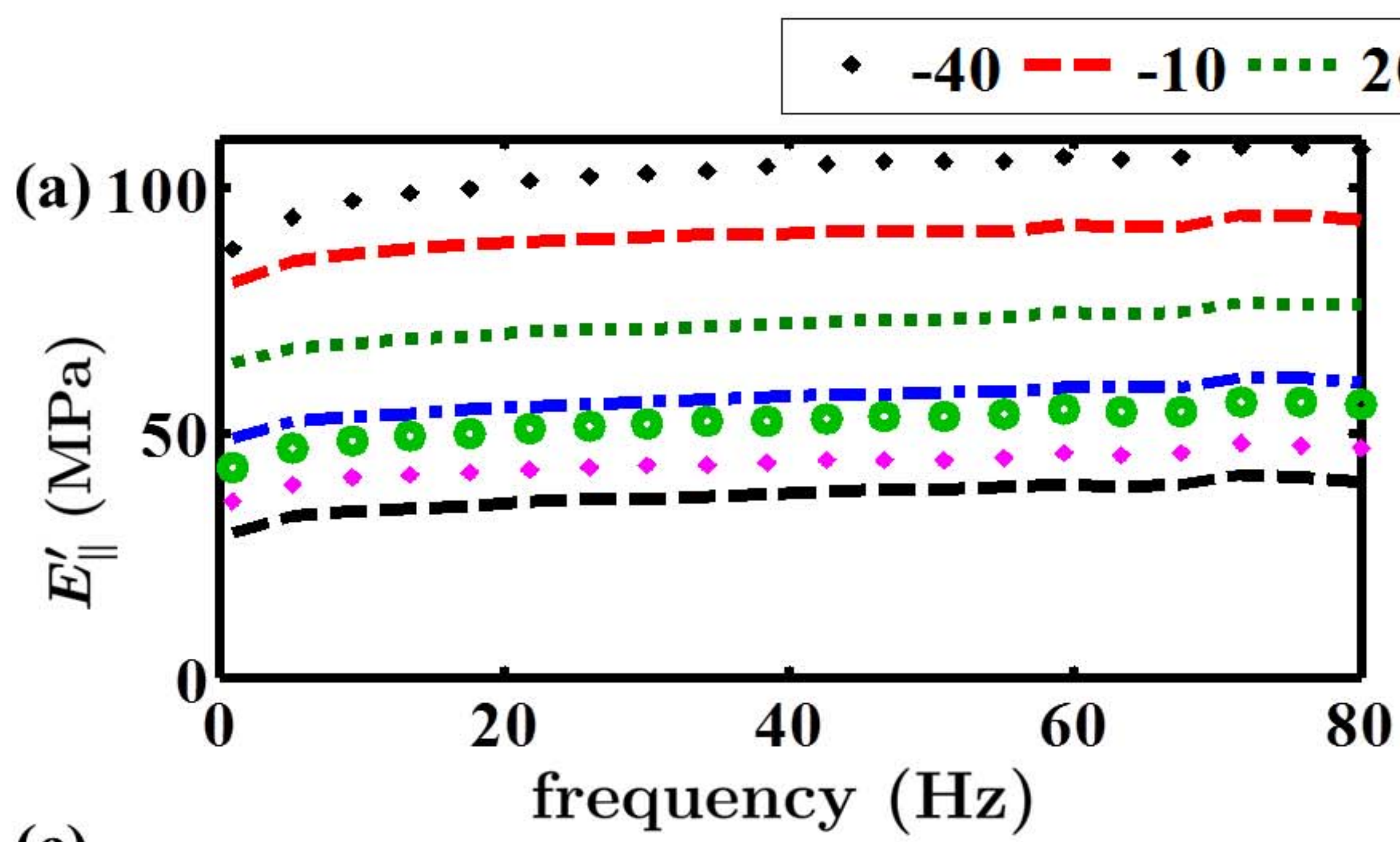

(c)

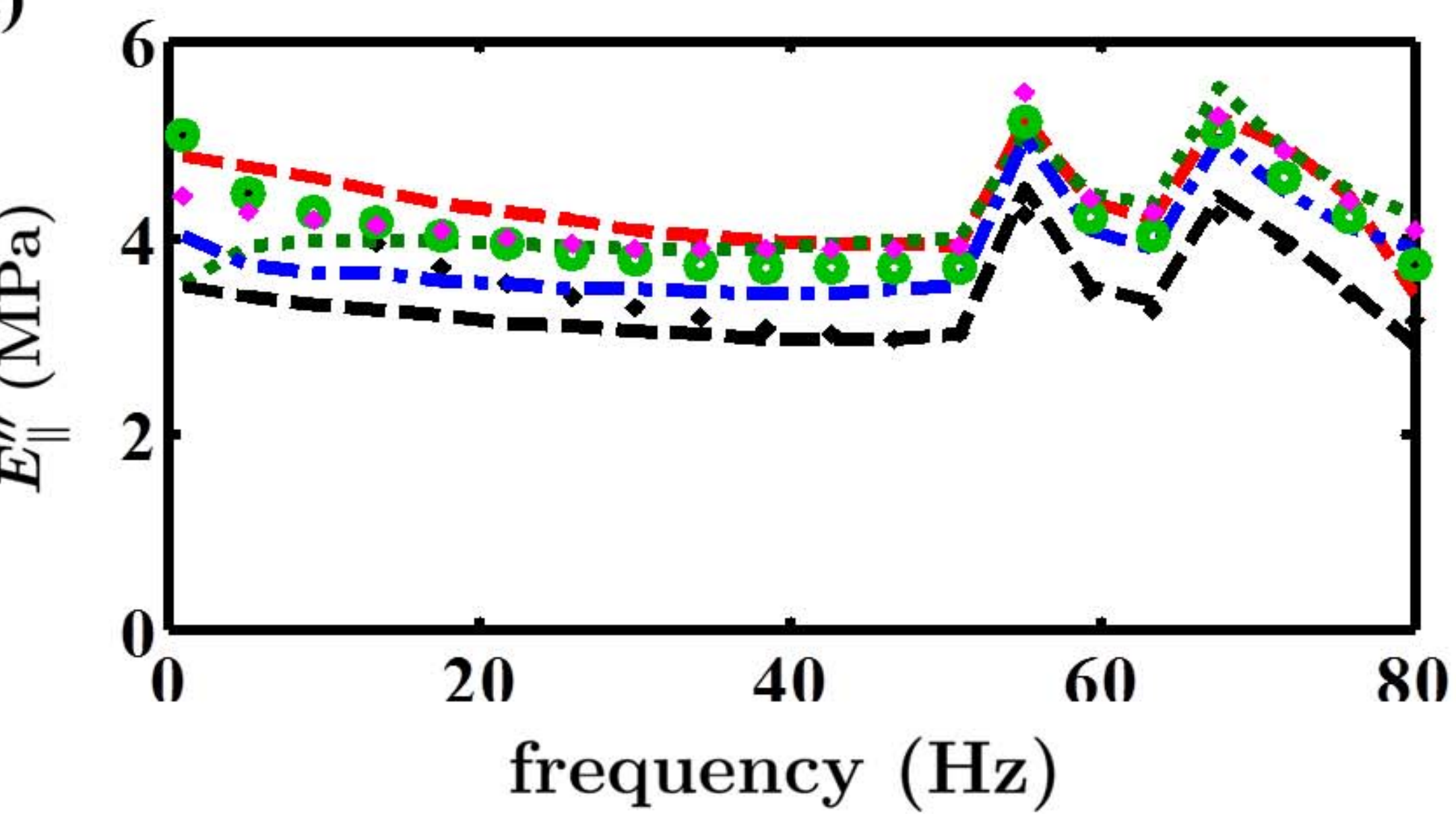

(b) 100

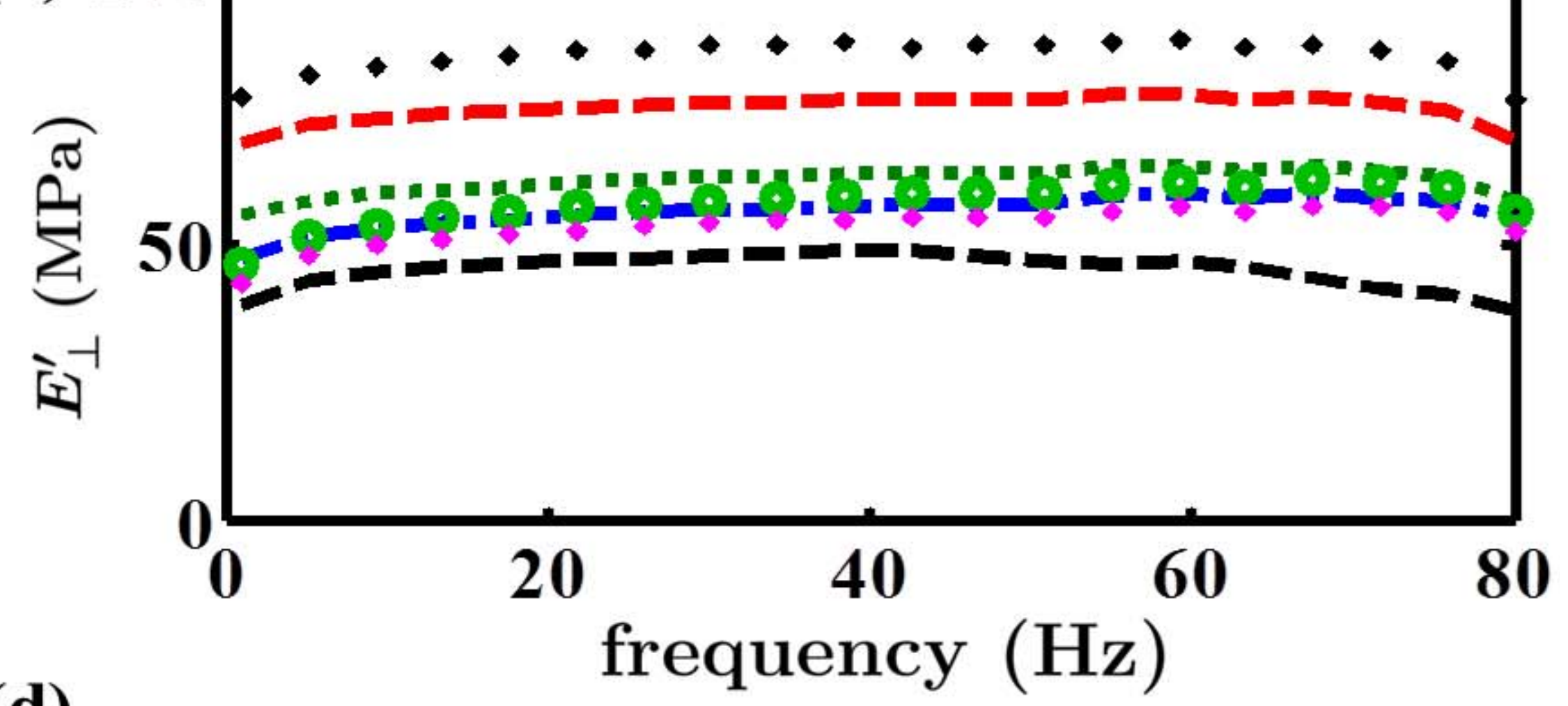

(d)

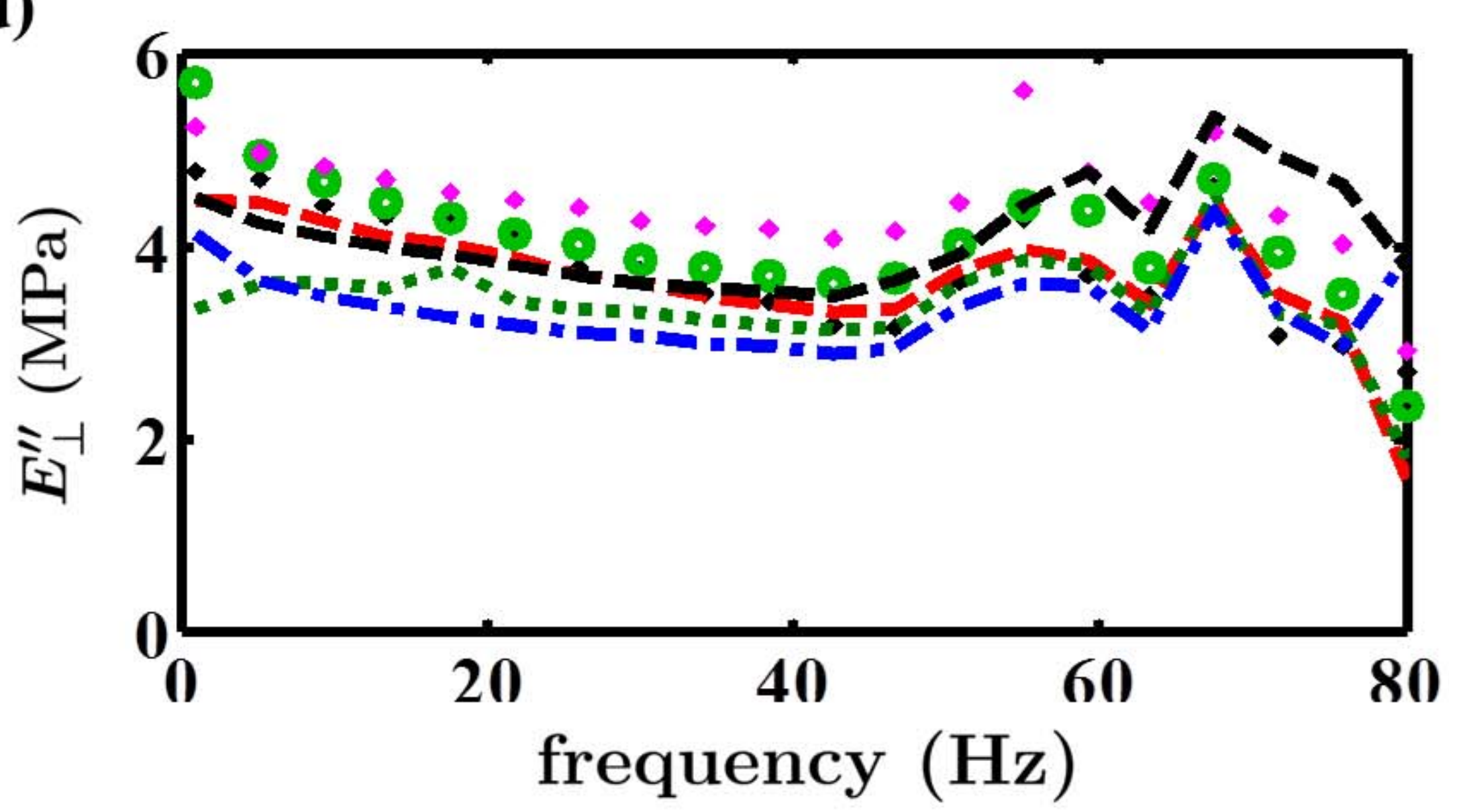




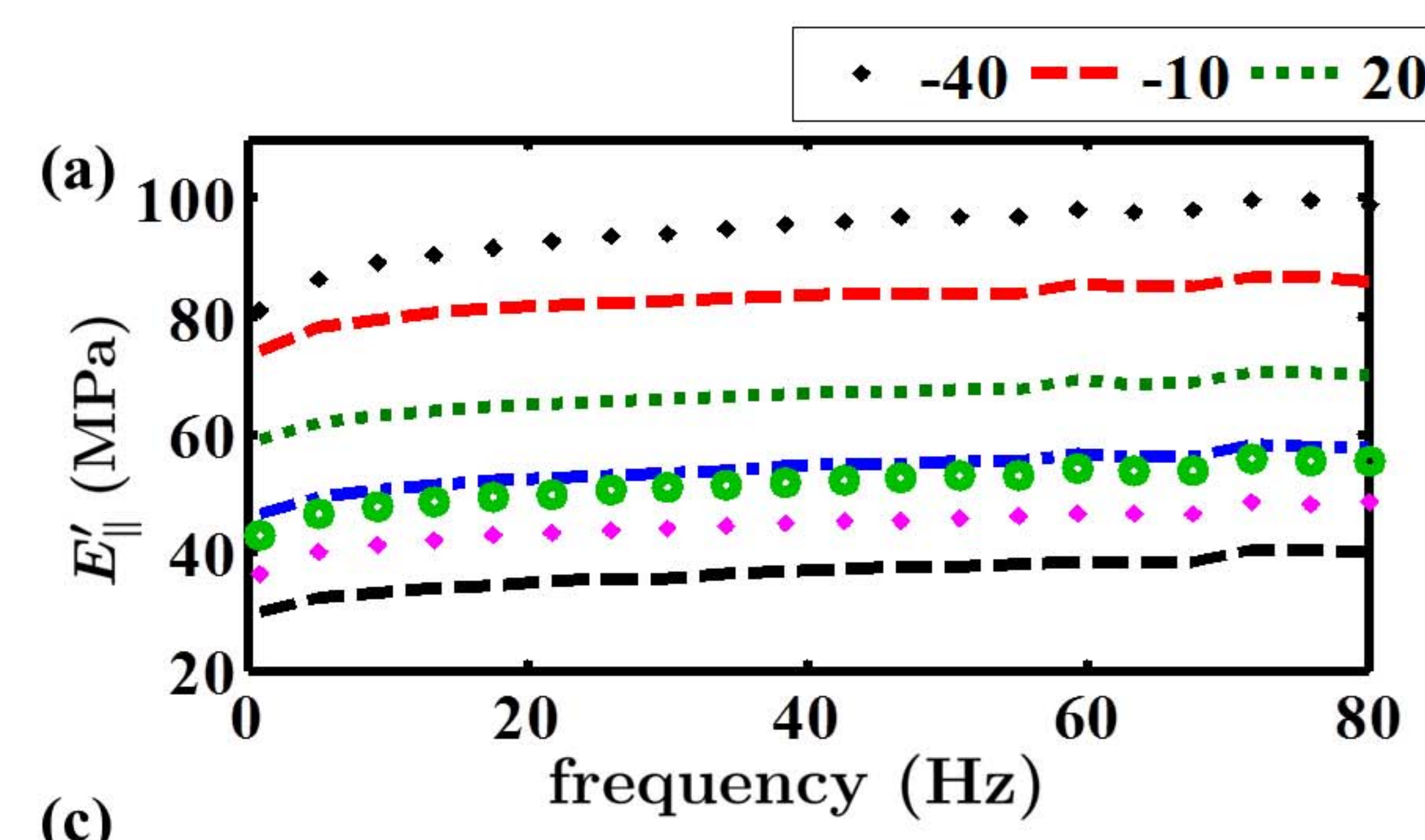

(c)
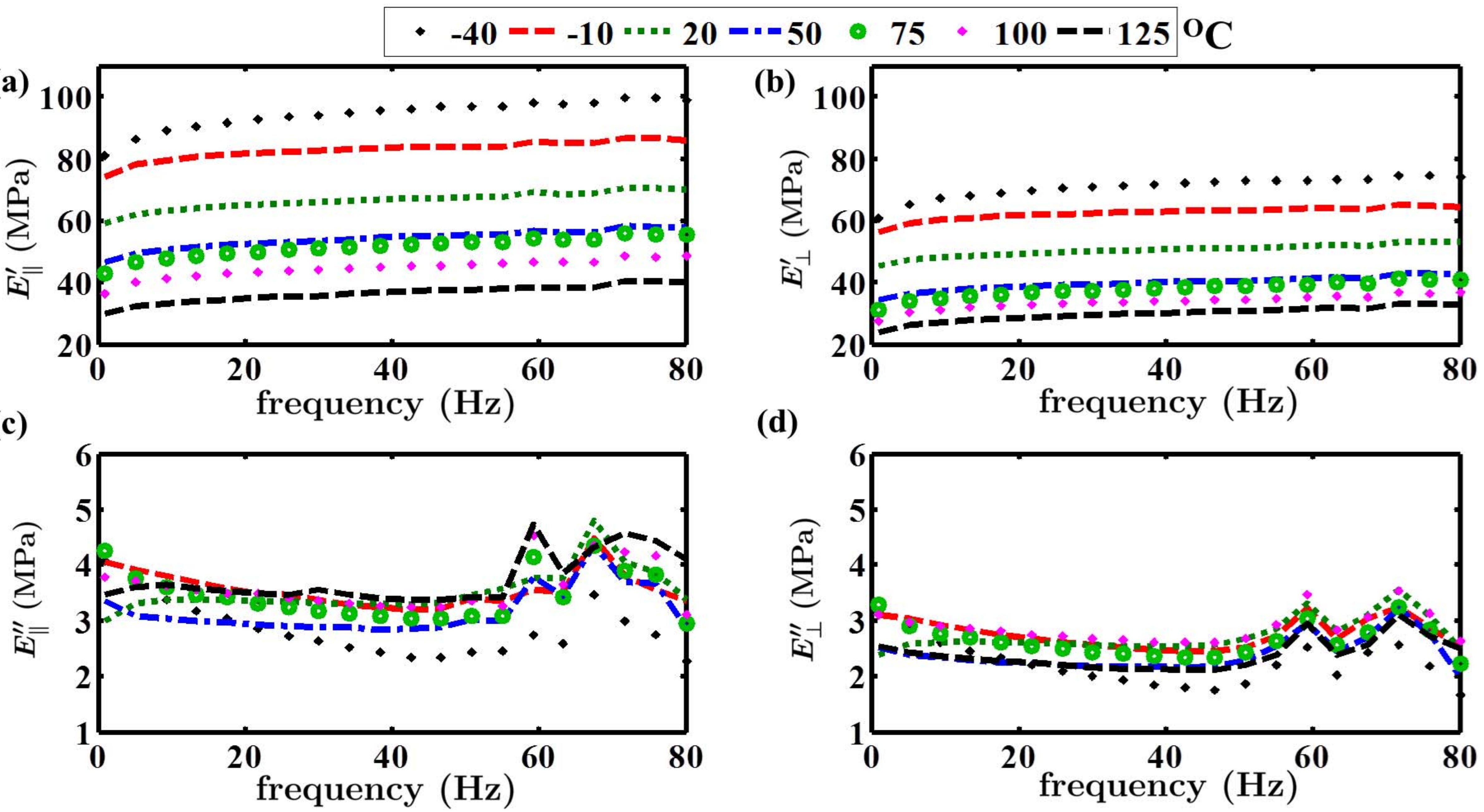


$$
\text { - }-40---10+\cdot 20--50 \bullet 75 \cdot 100--125{ }^{\circ} \mathrm{C}
$$
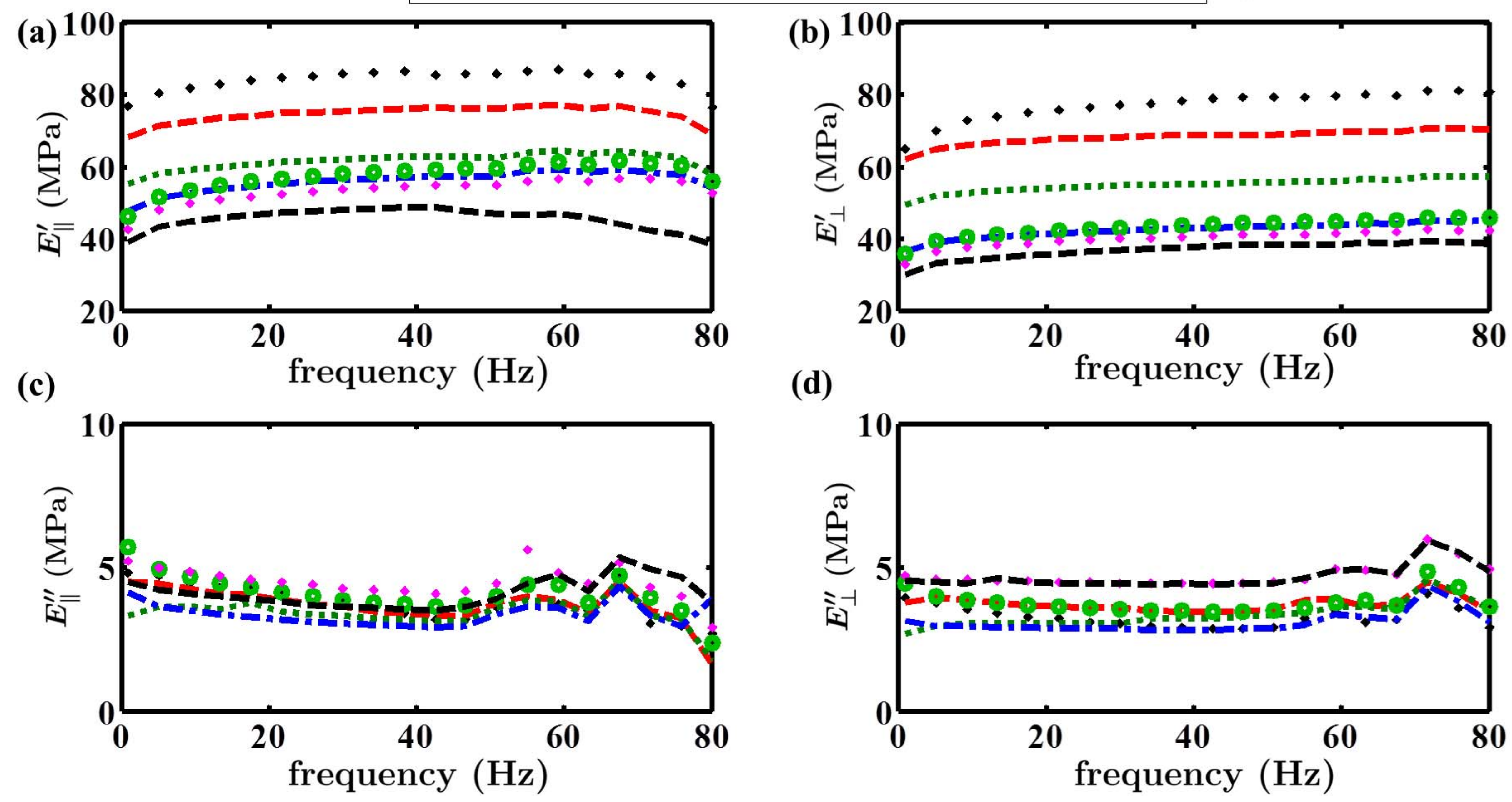

(d)

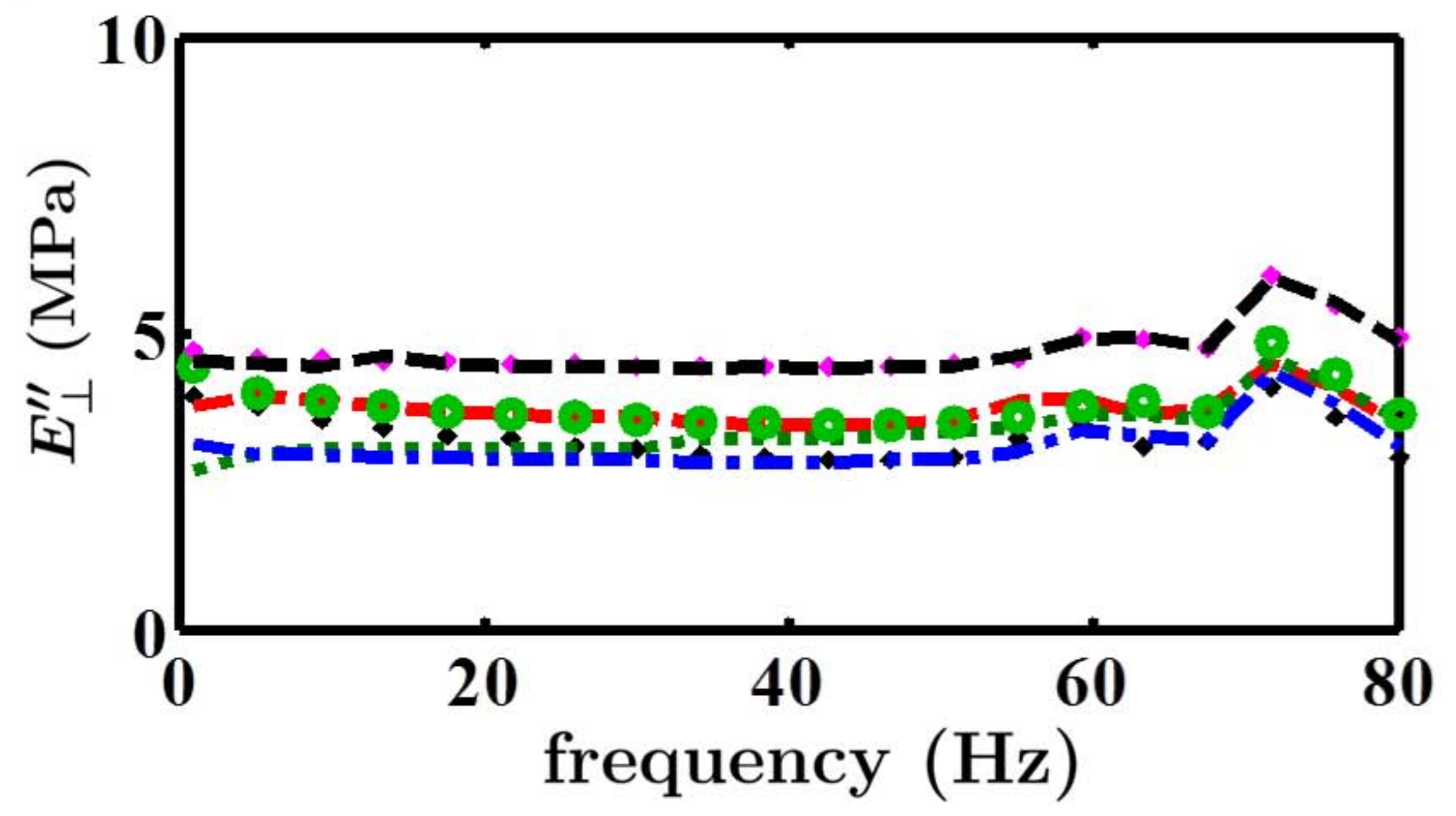



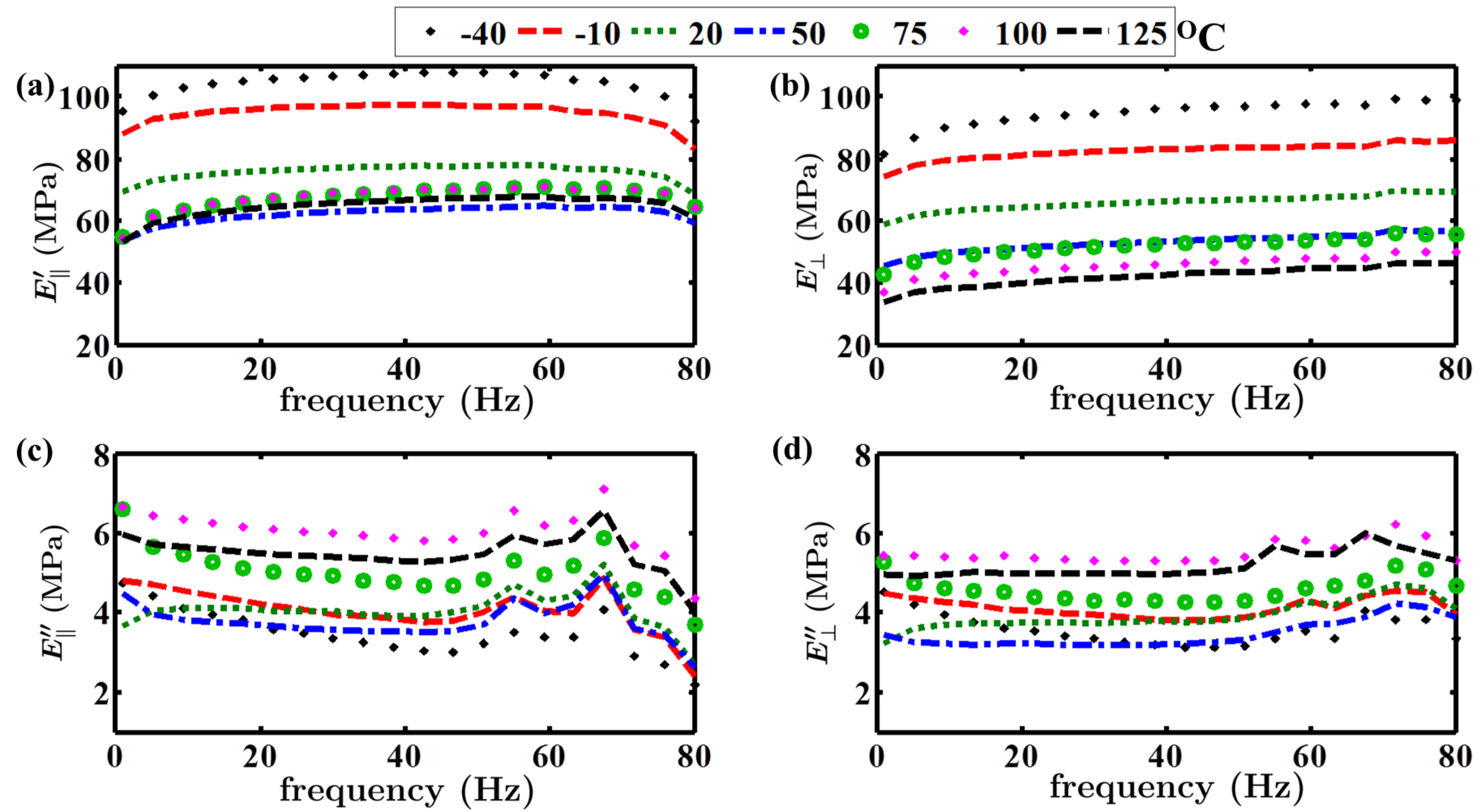

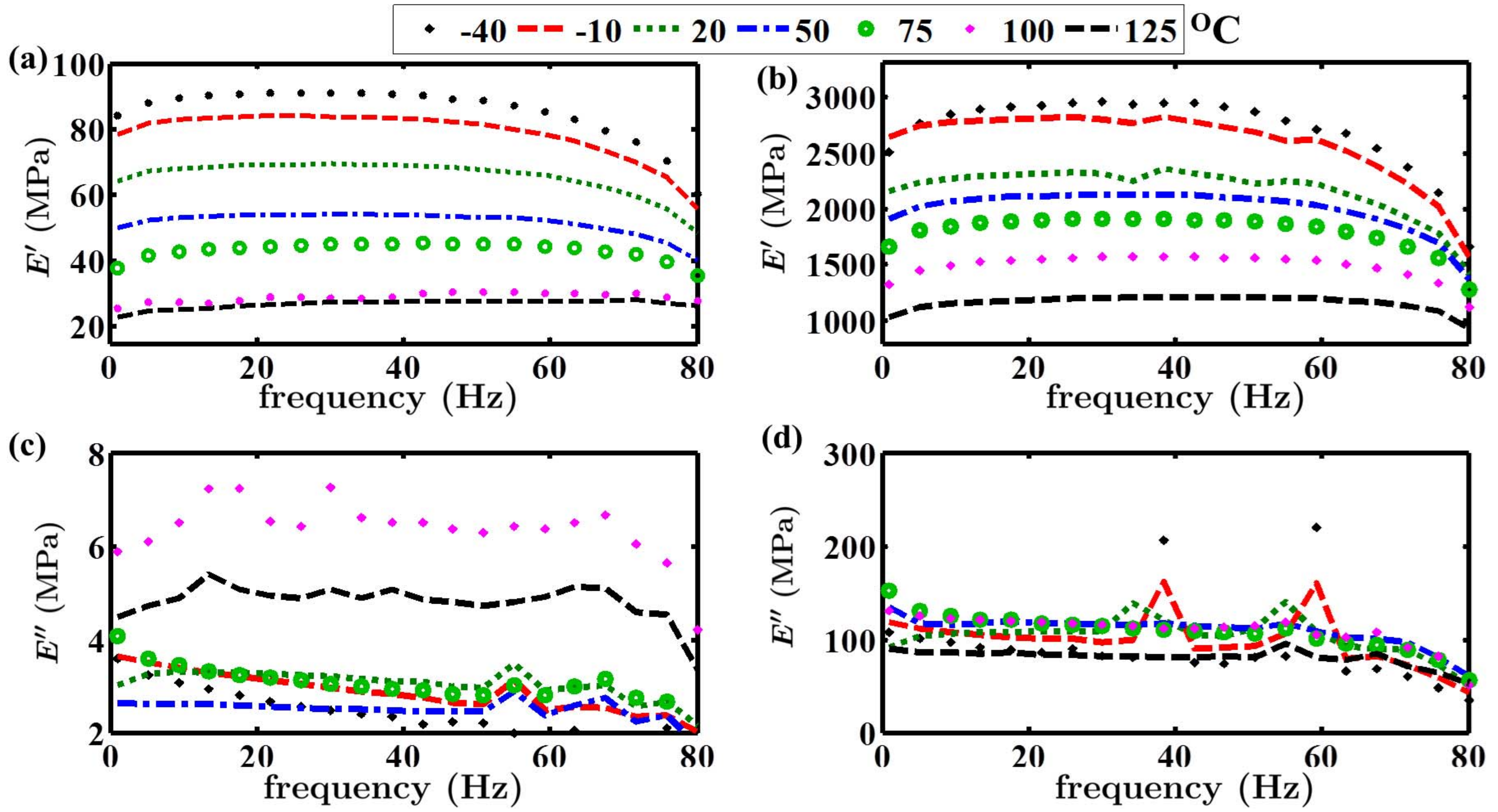


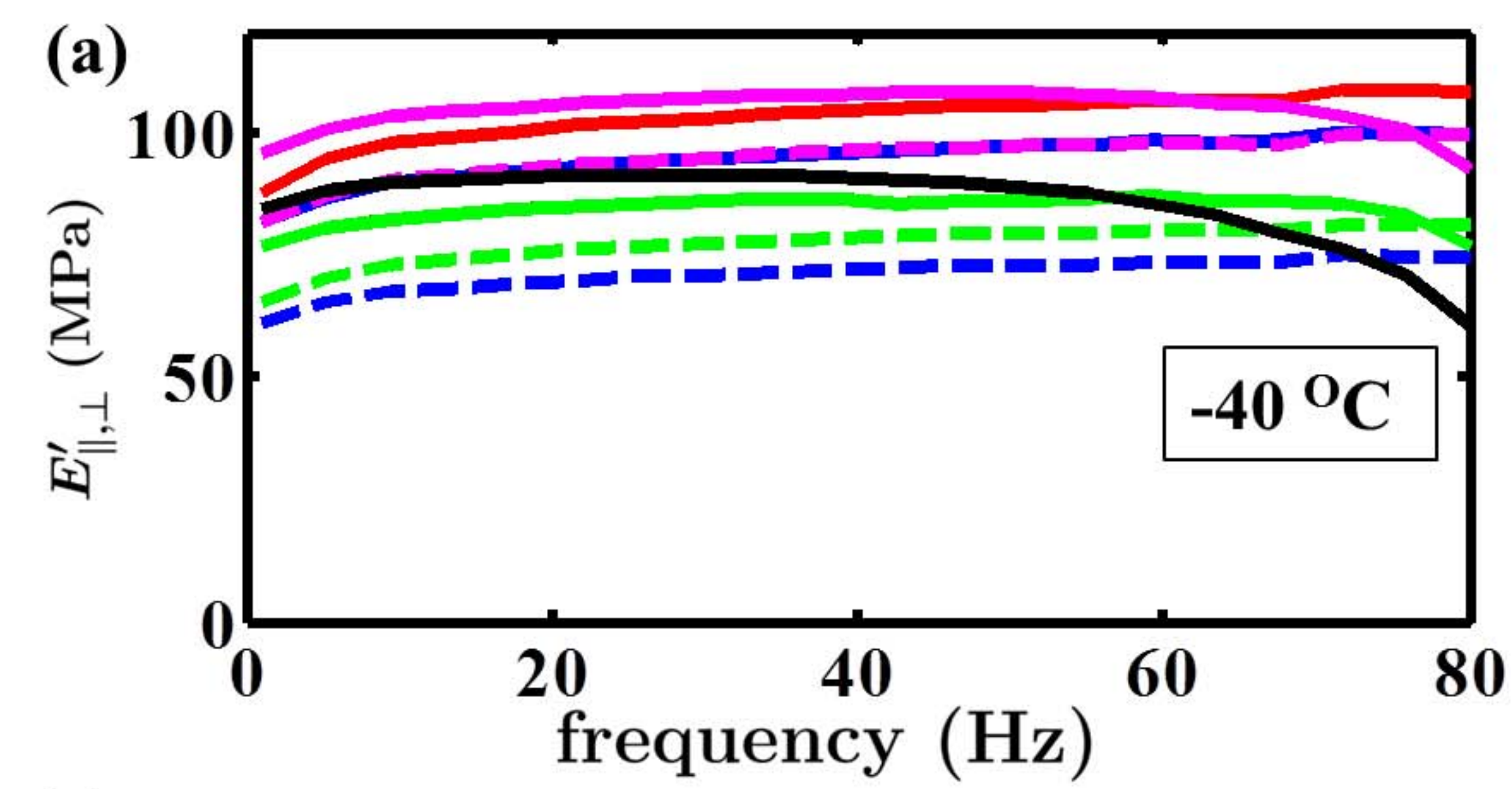

(b)

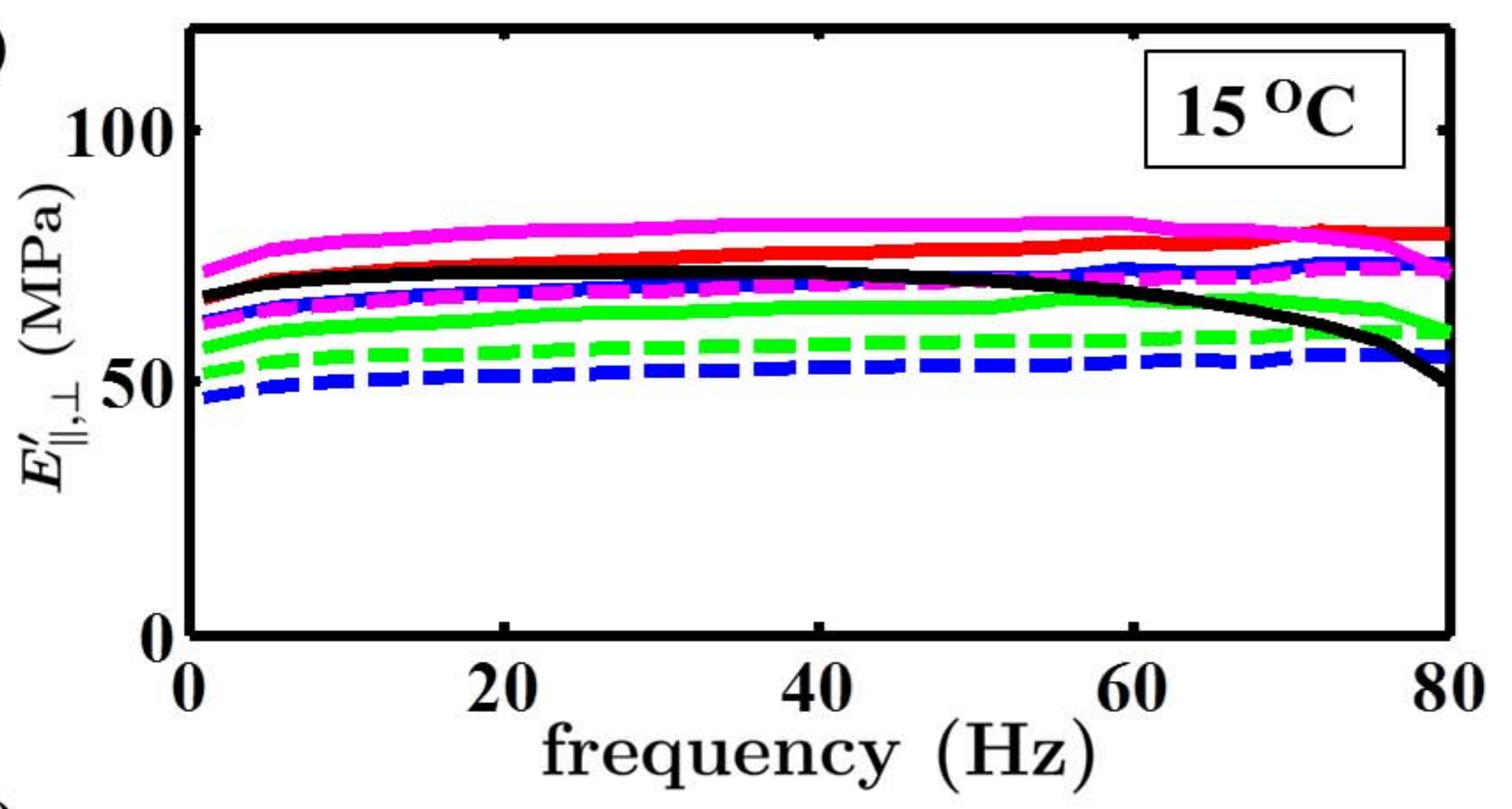

(c)

(d)
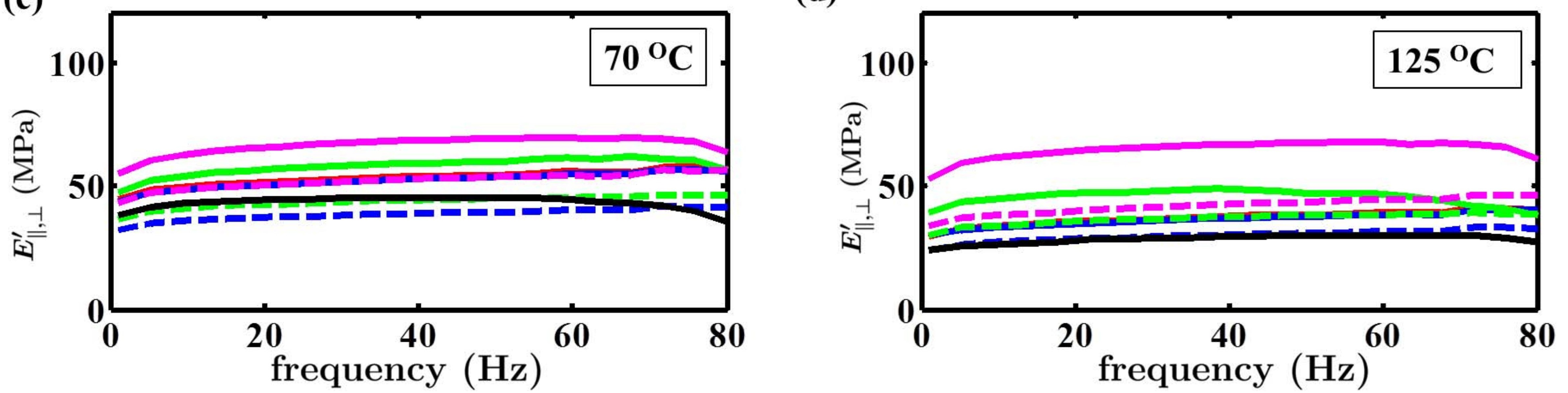

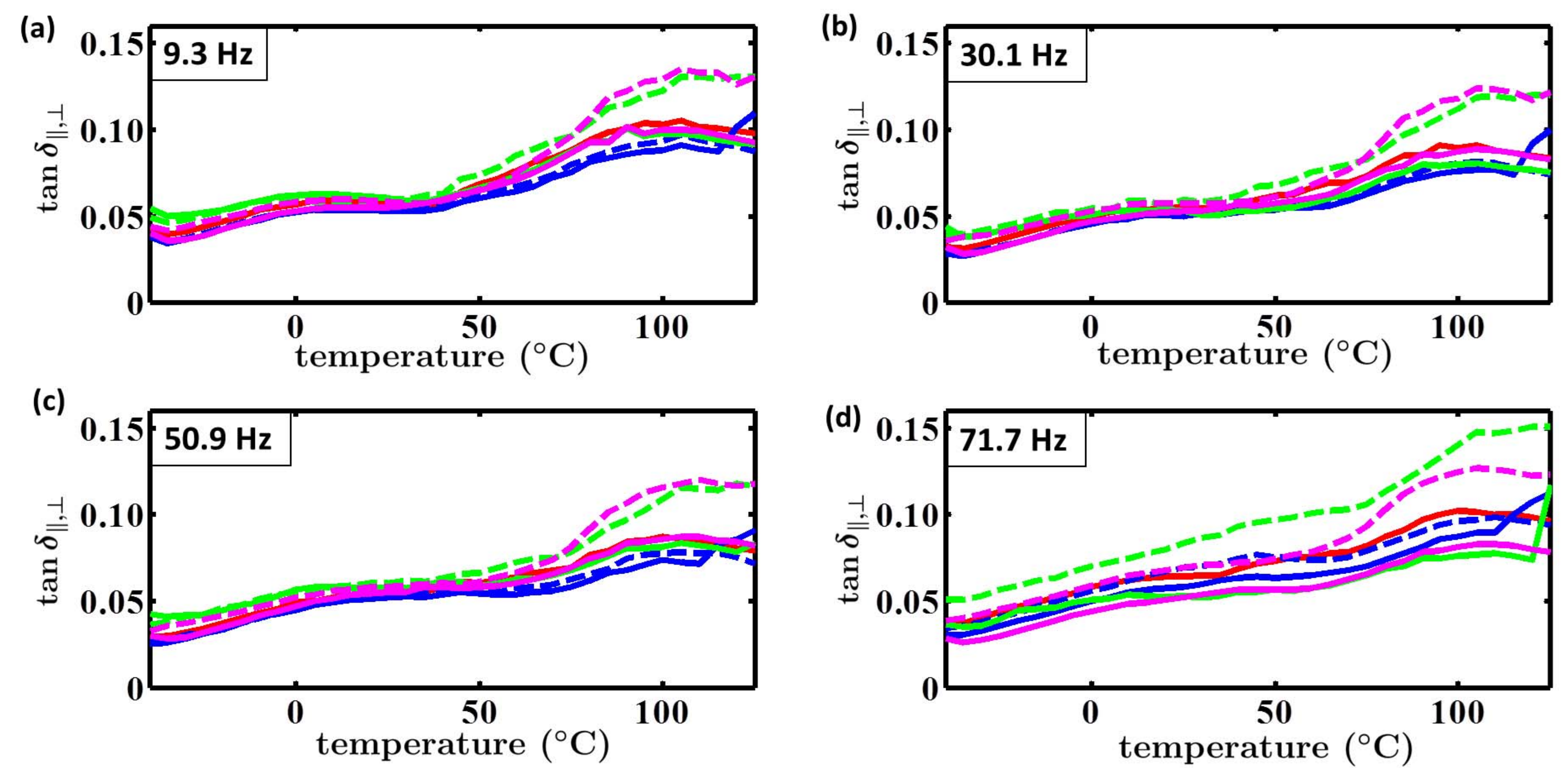